\title{
Public Reporting and a More Sustainable Army
}

Stuart D. Foltz, Gary L. Gerdes, Michelle J. Hanson,

David A. Krooks, and Chris C. Rewerts
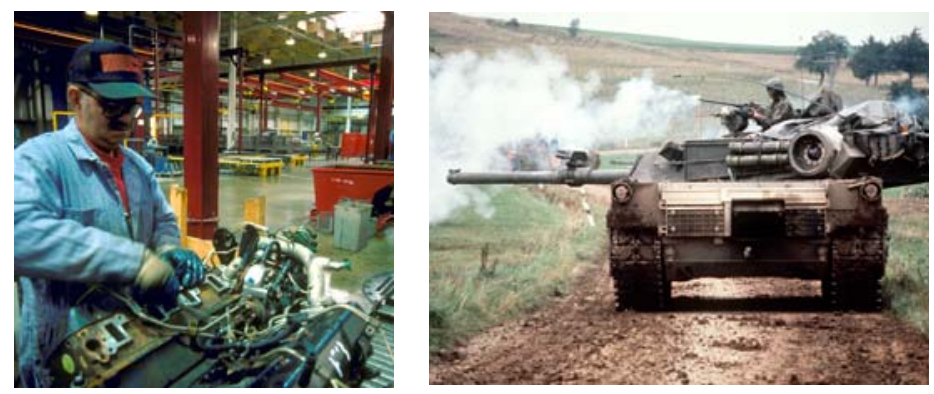

Vision, Goals, Strategy, Implementation \& Reporting: Improving Army Sustainability
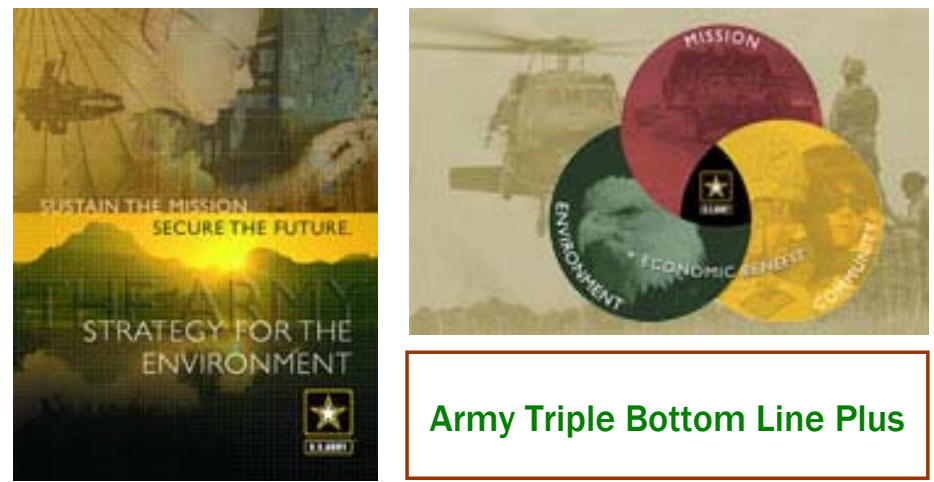

Army Triple Bottom Line Plus 


\section{Public Reporting and a More Sustainable Army}

Stuart D. Foltz, Gary L. Gerdes, Michelle J. Hanson, David A. Krooks, and Chris C. Rewerts Construction Engineering Research Laboratory (CERL) U.S. Army Engineer Research and Development Center 2902 Newmark Dr.

Champaign, IL 61822-1076

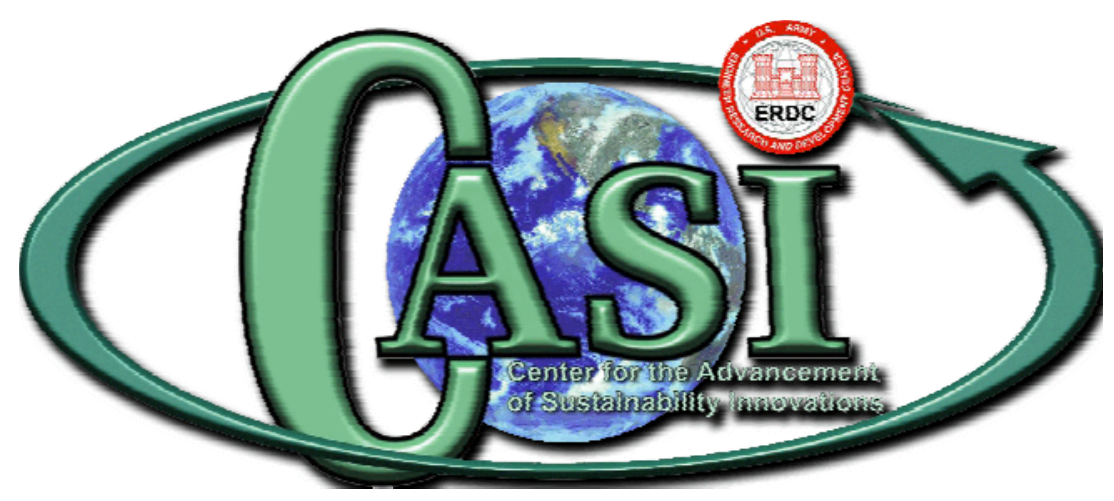

Final Report

Approved for public release; distribution is unlimited.

Prepared for U.S. Army Environmental Policy Institute

Arlington, VA 22202

Under MIPR 7LDATAEP17 


\begin{abstract}
The United States Army has embraced the goal of incorporating sustainability into its operations, all the while meeting its primary mission to defend the United States. The Army also has indicated a desire to be both transparent and accountable, so it has adopted a recognizable reporting framework - as outlined by the Global Reporting Initiative (GRI). This review considers the Army's response to the GRI framework in its recent sustainability report, and points out opportunities to strengthen both. It also makes recommendations to improve the Army's reporting and goal-setting efforts by making them more meaningful and more measurable. Such changes are necessary to achieve full sustainability, especially given the many challenges facing an organization as large and diverse as the Army. While making these changes, progress must be communicated to both internal and external audiences especially the general public - in clear and substantive terms. This report further outlines how Army personnel can become leaders in global sustainability reporting and suggests that numerous benefits will result from setting well-articulated, appropriately scaled goals and tracking progress toward those goals over time.
\end{abstract}

DISCLAIMER: The contents of this report arenot to beused for advertising, publication, or promotional purposes. Citation of trade names does not constitute an official endorsement or approval of the use of such commercial products. All product names and trademarks cited are the property of their respective owners. The findings of this report are not to be construed as an official Department of the Army position unless so designated by other authorized documents. 


\section{Executive Summary}

Sustain the Mission, Secure the Future: Army Sustainability Report FY 2007, was the Army's first attempt at annual sustainability reporting. It shows the Army's willingness to exhibit the transparency necessary to gain the public trust. In The Army Sustainability Report FY 2007, the Army commits to reporting regularly and transparently on its journey toward sustainability, using the framework provided by the Global Reporting Initiative (GRI). The framework developed by GRI is designed to help organizations measure and report their sustainability performance.

The objectives of this report are to review the Army's approach to sustainability reporting and to look for opportunities to strengthen it. To do this, an assessment was made of the state of commonly communicated sustainability practice and reporting among business and industry, as it relates to the Army's unique composition and mission. This review examined the GRI framework for Army application and the Army Sustainability Report (May 2008 draft version). A discussion of additional tools and applications that might advance sustainability in the Army, as well as a review of how other organizations report on their sustainability is also included.

The Army has embraced the challenge of reporting as it prepared The Army Sustainability Report for 2007. This report describes the Army's "triple bottom line-plus" (TBL), progress made in implementing the 2004 Army Strategy for the Environment (ASE), as well as the Army's first GRI report. By combining elements of the strategy, vision, goals, and reporting, the Army has taken great strides to link assessment of where it is with where it wants to be. The Army has few peers in size or complexity who are undertaking such ambitious steps toward sustainability, and therefore, must forge paths where none currently exist.

The Army Sustainability Report is not a single-year effort. It will be annually updated so that both the Army and its stakeholders are able to see trends over time. Following are suggestions for how the Army might build on the initial foundation in subsequent years' reports.

- Since the intended audience for The Army Sustainability Report is the general public, the report must be more elementary in its discussions and more explicit in its findings. The Army Sustainability Report 
would benefit from stronger linkages between the ASE and TBL portions of the report, and the GRI section. Such links should help the reader see the connections between the data presented, Army goals as they are articulated, and the progress the Army intends to make. The report should make explicit how the information provided helps to make the Army more sustainable. This is important, not only for most transparently reporting what the numbers mean, but also as a way to help readers understand the Army's operational status.

- The Army has unique characteristics, particularly its operational activities as carried out in a battle space. Simply put: to many outside the military community, the destructive methods used in Army operations are a stark contrast to most nonmilitary visions of sustainability. This seeming discrepancy can be better acknowledged and put into perspective in the Army Sustainability Report. In addition, the Army is currently at war, making some types of reporting difficult to use in representing trends, because deployment for war results in both a huge use of resources and other impacts on the entire organization. Part of the GRI reporting process is to consider the boundaries of the report; application of the criteria that GRI provides indicates that the operational activities of an Army at war still fall within the bounds of what should be reported. Careful consideration needs to be given to how to report the sustainability of contingency operations in such a way that they are acknowledged, while the parts of the Army's operations that are more comparable to nonmilitary organizations are tracked for trends.

- The GRI framework leaves the question of the significance of what is reported and the significance of any given report itself entirely up to the reader. It is our considered view that adding a scoring function to the GRI framework would ultimately lead to more substantive reporting.

- Getting an 'A' on a GRI report is simply a function of reporting on more items. Obtaining an ' $A$ ' on its report, though in itself laudable, need not be a high priority. The evolution of its public reporting process would be better served by carefully reviewing the report with respect to GRI's principles for defining content and quality.

- The Army could show leadership by promoting the improvement of the GRI guidelines. GRI is a useful tool for organizing and standardizing sustainability reporting. However, GRI falls short by not providing the guidance necessary to actually measure an organization's sustainability. The Army should consider participation in the ongoing efforts by the Global Reporting Initiative to improve the GRI guidelines. 
- Regarding the diligent use of GRI guidelines, the Army does well compared to other organizations. Few, if any, corporate sustainability reports follow the GRI protocol at the level of detail present in the Army report. From this standpoint, the Army has demonstrated significant leadership, and has set a benchmark for other organizations.

- If the intent for using the GRI G3 guidelines is to enhance transparency, then the information should be explicitly provided, including any types of analysis or aggregation that were used to take data from the source and make it usable as a GRI metric. Such an approach will also ensure that subsequent GRI reports can replicate these same processes and thus, help to make them comparable and trendable relative to previous reports.

- The Army collects and reports vast amounts of data, driven by many needs and requirements. It is natural to begin making sustainability measurements using available data; however, care must continually be taken to evaluate and adapt the type of data used so that it has the power to measure what yields the best picture of sustainability.

To effectively implement a major improvement in a large organization's sustainability, there are a number of general steps that may be considered. These steps may include the use or development of various methods and tools that provide awareness, determine available resources, measure baseline resource use, or measure subsequent progress and success toward goals.

Goal-setting is one important step that the Army is currently embracing through the Installation Sustainability Planning (ISP) process and the Army Strategy for the Environment. The initial ISP goals set by installations have been focused primarily on reducing resource use and increasing the supply of renewable resources. While these goals are quantitative, they are generally based on qualitative and sometimes even arbitrary criteria. Goal-setting for the Army could be improved by including a quantitative analysis of what is sustainable. Goals are important, but they must be well articulated and appropriately scaled, and they must facilitate the tracking of improvements over time.

Setting goals for reduction in resource use and increasing the supply of renewable resources can benefit the Army, even if the goals are not directly tied to a sustainable outcome. Setting a goal using an arbitrary percentage reduction is insufficient to serve sustainability. The Army would be well served by showing a consistent preference for sustainable outcomes that 
can be tied to a global, regional, or local resource limitation. It is also important to monitor how the goals are reached, to ensure the mission is not compromised.

The Army has embraced the goal of becoming more sustainable, articulated a desire to be transparent as it journeys down the path to sustainability, and adopted the GRI reporting framework as a means to demonstrate its progress on that path. By taking these actions, the Army has made clear its commitment to be a leader in the reporting community.

There is ample room in the reporting community for improved (i.e., more substantive) reporting. Improving its sustainability reports by extending their scope to achieve a GRI A-level is a reasonable near-term goal for the Army, even though A-level reports alone will not lead to progress on the path to sustainability.

We have also seen that refining the goal setting process is another way in which the Army can show leadership. Showing the reporting community how to set well-articulated, appropriately scaled goals, and how to track progress against them, is yet another way in which the Army can lead.

Reporting is a necessary task for engaging stakeholders, but it is only a small part of the process of moving toward sustainability. A GRI report is not the vehicle to address most of the sustainability issues that the Army is concerned about.

Great leadership will not be shown either by reporting or by goal setting. Instead, the challenge facing the Army (and the highest form of leadership it can demonstrate) is to figure out systematic, elegant, reproducible methods that help in making choices between competing alternatives. 


\section{Contents}

Executive Summary ...................................................................................................................... ii

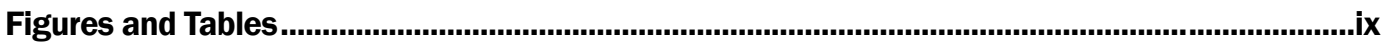

Preface

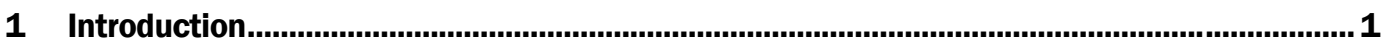

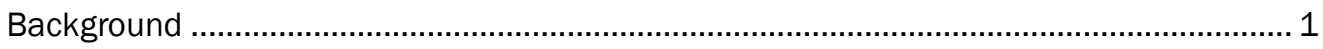

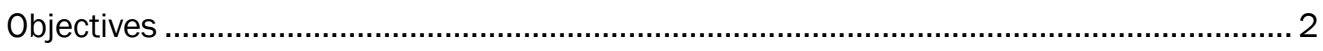

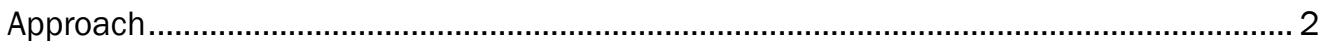

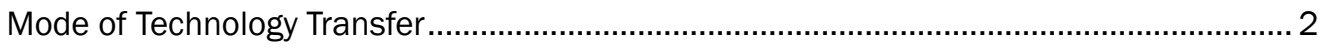

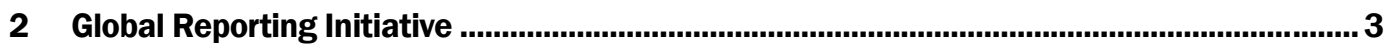

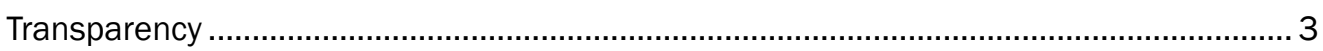

GRI in General

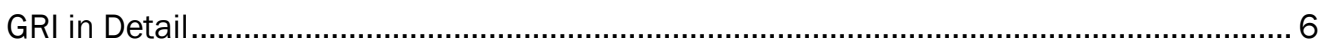

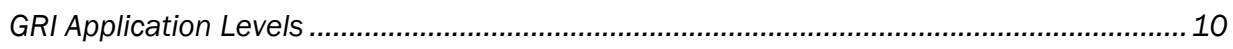

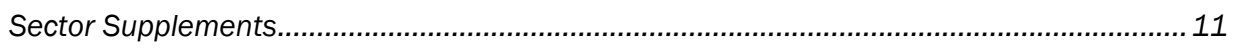

Review of GRI Environmental Indicators ................................................................. 12

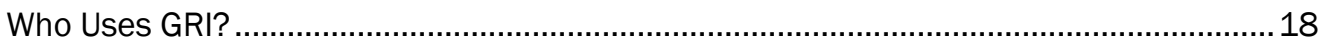

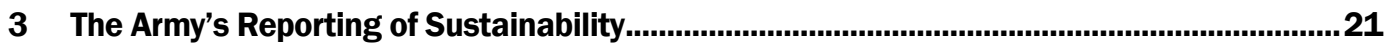

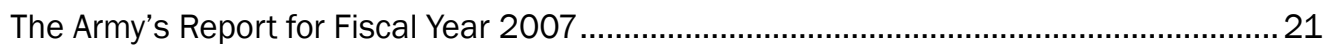

Review of the Army's Reporting of GRI Environmental Indicators ......................................22

How the Army can Improve Reporting of Sustainability .................................................. 24

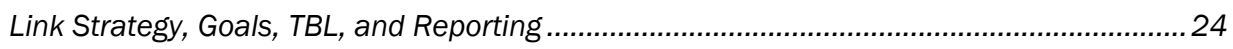

Accommodate the Unique Mission of the Army ................................................................ 24

Construct the Report as an Annual Update....................................................................... 25

Incorporate Updates from the Installation Sustainability Program .......................................26

Actively participate in the evolution of the GRI G3.......................................................... 27

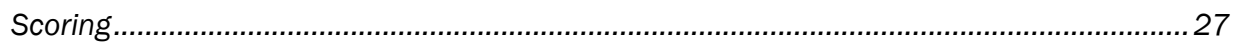

Improve the data being used as Indicators ..................................................................... 27

Transforming data and reporting to facilitate the basis of sustainability reporting............... 30

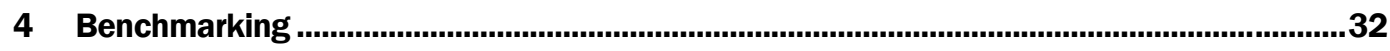

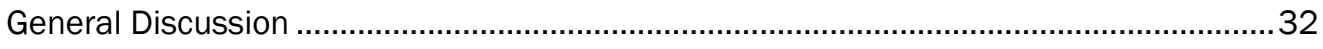

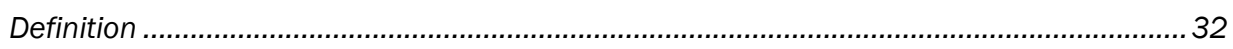

Army Sustainability Goals, and Reporting Using GRI ....................................................... 33

Using Reports from Other Organization as Benchmarks................................................. 33

Sustainability Reporting by Other Organizations ..............................................................34

The United Kingdom “Ministry of Defence Sustainable Development Report”...................... 35

Australian "Defence Public Environment Report" ................................................................. 35

The University of North Carolina Chapel Hill 2007 Campus Sustainability Report ................ 36

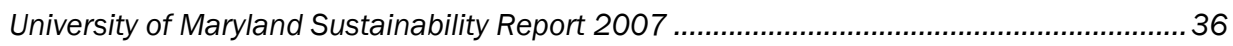


5 Advancing Sustainability Practice - Planning and Implementation .......................................37

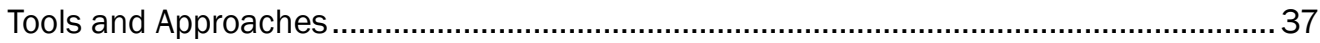

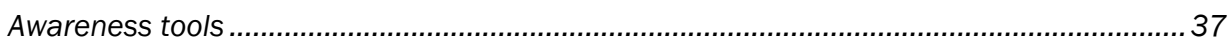

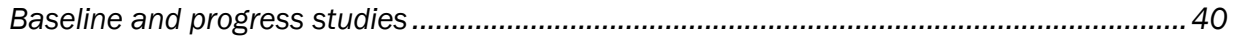

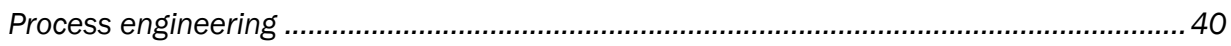

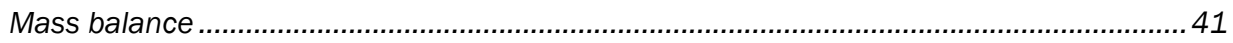

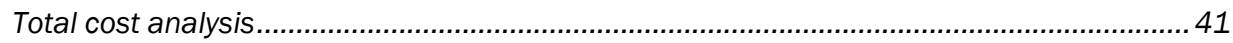

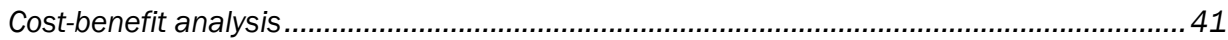

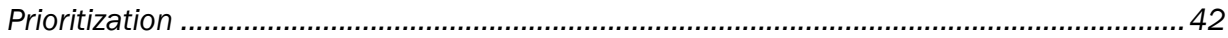

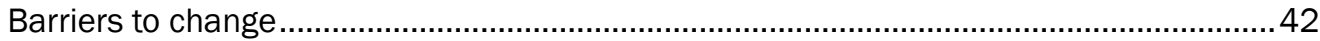

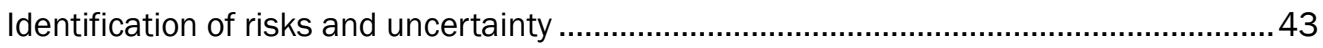

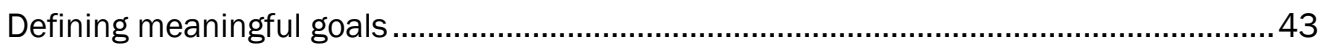

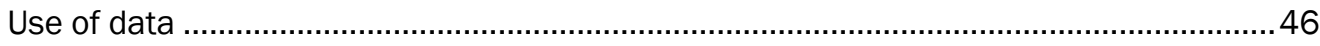

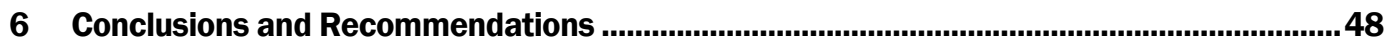

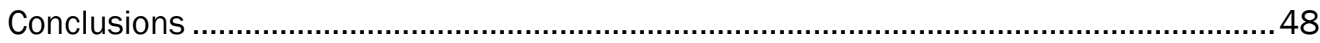

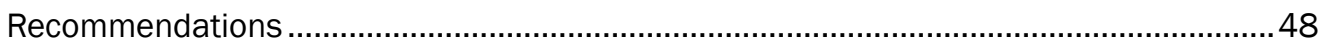

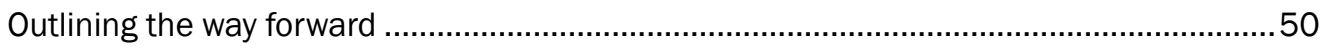

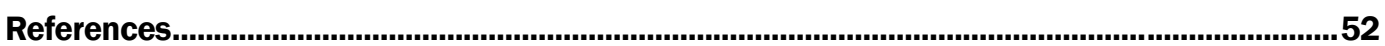

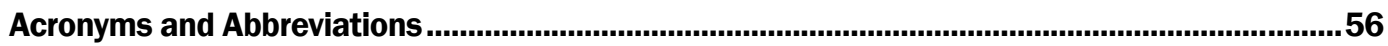

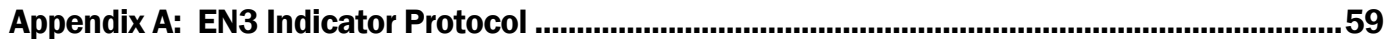

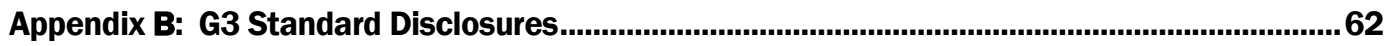

Appendix C: Who Reports under GRI?

Appendix D: Review of Documents Referenced in Army Sustainability Report for GRI

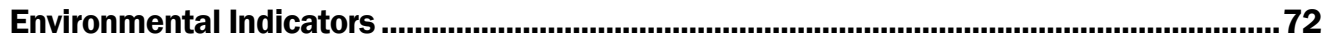

Appendix E: Review of Army Sustainability Report responses for GRI EN indicators.................77

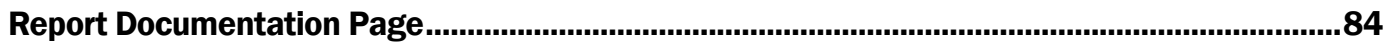




\section{Figures and Tables}

\section{Figures}

1 GRI application level criteria (NOTE: table reproduced from GRI information with permission)

\section{Tables}

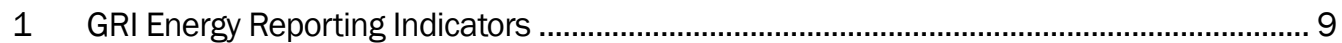

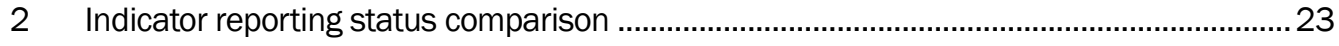

3 Indicator reporting status (as per Appendix E) .............................................................. 23 


\section{Preface}

This study was conducted for the Army Environmental Policy Institute (AEPI) under a project titled "Review and Enhance the Army's Sustainability Decision Making Process," via MIPR7LDATAEP17. The AEPI Director was Michael Cain and technical monitors were David Sheets and J ohn Fittipaldi, of AEPI offices at 1550 Crystal Drive, Suite 1301, Arlington, VA 22202.

The work was managed and executed by the Business Processes Branch (CN-B) of the Installations Division (CN), Construction Engineering Research Laboratory (CERL). Significant contributions were made by researchers from other branches at CERL, including Land \& Heritage Conservation Branch (CN-C), Environmental Processes Branch (CN-E), and Materials \& Structures Branch (CF-M). Michelle Hanson is Chief, CEERD$\mathrm{CN}-\mathrm{B}$ and the Principal Investigator at CERL for this study, and J ohn Bandy is Chief, CEERD-CN. The associated Technical Director was William Goran, CEERD-CV-T. The Deputy Director of ERDC-CERL is Dr. Kirankumar V. Topudurti, and the Director of ERDC-CERL is Dr. Ilker R. Adiguzel.

CERL is an element of the U.S. Army Engineer Research and Development Center (ERDC), U.S. Army Corps of Engineers. The Commander and Executive Director of ERDC is COL Gary E. J ohnston, and the Director of ERDC is Dr. J ames R. Houston.

Notation on authorship: The listing of authors for this report is given in alphabetical order for convenience. It is not indicative of the level of any author's individual contribution. 


\section{Introduction}

\section{Background}

The Army has taken great strides toward incorporating sustainability into its culture, as evidenced by three documents: The Army Strategy for the Environment, the draft Strategic Plan for Army Sustainability, and the Army Sustainability Report FY 2007.

At the core of The Army Strategy for the Environment is "a missionoriented approach based on the principles of sustainability." Those sustainability principles are: (1) to safeguard human health, (2) to improve quality of life, and (3) to enhance the natural environment, while meeting the primary mission to defend the United States - its people, its land, and its heritage. Thus, for the Army, the triple bottom line of sustainability is mission, environment, and community; adding an economic dimension to this set yields "the triple bottom line plus."

The draft Strategic Plan for Army Sustainability contains explicit sustainability goals that demonstrate the Army intends to aggressively pursue sustainability. The Army Sustainability Report FY 2007, the Army's first attempt at annual sustainability reporting, shows the willingness of the Army to exhibit the transparency necessary to maintain the public trust. Embracing the goal of becoming more sustainable adds a new system perspective to the Army's view of its operations and represents a significant change in Army culture, and in its way of doing business.

The Army has developed considerable momentum through its Installation Sustainability Program, and key to meeting the challenge of The Army Strategy for the Environment is to spread that momentum into the remaining Army operational domains and to demonstrate consistent progress on the journey it has undertaken.

One method that an organization might use to articulate its progress, to both internal and external constituencies, is to adopt a reporting regime and rigorously employ it in analyzing operations. Such a regime could provide a framework both for goals and for progress toward meeting them. In its first sustainability report (The Army Sustainability Report FY 2007), the Army commits to reporting regularly and transparently on its journey 
toward sustainability, using the framework provided by the Global Reporting Initiative (GRI).*

The Army's commitment to public reporting of progress naturally leads to detailed consideration of the reporting framework. The intent of our reviews, though critical, is to help the Army progress toward becoming more sustainable.

\section{Objectives}

The objectives of this investigation are:

1. Review the framework under which the Army has decided to make its reports (GRI).

2. Review the Army's first sustainability report, specifically to consider its responsiveness to the GRI reporting guidelines

3. Set the Army's sustainability report in the broader context of reports by similar public organizations.

4. Look briefly at the setting of sustainability goals and other ways in which sustainability practice might be advanced throughout the Army.

\section{Approach}

This work reviewed the GRI framework under which the Army has decided to make its reports and also, the Army's then-draft sustainability report, specifically to consider its responsiveness to the GRI reporting guidelines.

\section{Mode of Technology Transfer}

This report will be made accessible through the World Wide Web (WWW) at URL: http://www.cecer.army.mil

\footnotetext{
* The GRI is a worldwide, multi-stakeholder network which has pioneered the development of the world's most widely used sustainability reporting framework.
} 


\section{Global Reporting Initiative}

In successive drafts of sustainability reports, the Army commits to reporting regularly and transparently on its journey toward sustainability, using the framework provided by the GRI. In this chapter of our report, we first introduce the notion of transparency, and then discuss the GRI framework.

\section{Transparency}

For the external public, reports can be divided into two broad types: financial reports and non-financial reports. The non-financial reports typically address environmental issues, broader corporate social issues, and even broader sustainability issues (McCarry 2002).

The notion of transparency is broad, running the gamut from fighting corruption (Transparency International, n.d.), to discovering funding sources that covertly support interest group propaganda (Media Transparency, n.d.), to the rather less political notions of financial reports (Bushman and Smith 2003, 65-87).

In the universe of information that is the Internet, the term "transparency" is even construed to mean full disclosure of all possible company information (even that which is typically considered internal, such as employee complaints), a practice at least one set of authors believes "boosts employee morale and performance, facilitates business partnerships, and helps responsible corporations attract socially conscious consumers and investors" (review of Tapscott and Ticoll 2003).

GRI guidelines (the framework the Army has chosen for non-financial sustainability reporting) do not offer a definition of transparency that will stand independent of the guidelines. Instead, the GRI's view appears to be that transparency will follow naturally from using its reporting framework.

The urgency and magnitude of the risks and threats to our collective sustainability, alongside increasing choice and opportunities, will make transparency about economic, environmental, and social impacts a fundamental component in effective stakeholder relations, investment decisions, and other market relations. To support this expectation, and to communicate clearly and openly about sustainability, a globally shared 
framework of concepts, consistent language, and metrics is required. It is the Global Reporting Initiative's (GRI) mission to fulfill this need by providing a trusted and credible framework for sustainability reporting that can be used by organizations of any size, sector, or location (GRI Reporting Guidelines 2006, 2).

Transparency can be defined as the complete disclosure of information on the topics and indicators required to reflect impacts and enable stakeholders to make decisions, and the processes, procedures, and assumptions used to prepare those disclosures. (ibid., 6)

The One World Trust (OWT), whose Global Accountability Project "aims in particular to generate wider commitment among global organizations to establish and adhere to common principles and values of accountability in the relationship with the people they affect; and to strengthen the capacity of civil society to engage in global policy and decision making processes," (Lloyd, Oatham, and Hammer 2007, inside cover) does provide a standalone definition of transparency:

Transparency is the provision of accessible and timely information to stakeholders and the opening up of organizational procedures, structures, and processes to their assessments. Doing so enables stakeholders to monitor an organization's activities and hold it to account for its commitments, actions, and decisions. (ibid, 11)

For OWT, transparency is one of four core dimensions of accountability; the other three are participation, evaluation, and complaint and response mechanisms. (ibid.) The latest version of OWT's weighted indicators for assessing an organization's transparency capabilities is available for download at the following URL:

www.oneworldtrust.org/index.php?option=com_docman\&task=doc_download\&gid=254\&ltemid=55

Clearly, an organization that reports under the GRI framework can achieve transparency in the sense intended by OWT. The attentive reader will already have surmised, however, that the degree to which an organization's report may be considered transparent depends almost entirely upon the goodwill and care of those who produce the report. Other potential flaws in reporting aside, it would be possible for an organization to report under the GRI framework and still be charged with "greenwashing," according to the following definition: 
Greenwashing is the unjustified appropriation of environmental virtue by a company, an industry, a government, a politician or even a nongovernment organization to create a pro-environmental image, sell a product or a policy, or to try and rehabilitate their standing with the public and decision makers after being embroiled in controversy. (sourcewatch.org n.d.)

A constructive defense against accusations of greenwashing is a disciplined and self-critical review by the reporting organization. Such a review should be sensitive both to what is addressed in the report and to what information is readily available, but remains unaddressed.

\section{GRI in General}

GRI is a not-for-profit entity involving a wide variety of stakeholders that includes business, civil society, labor, investors and accountants (GRI About GRI n.d.). GRI has developed a reporting framework intended to enable organizations to report publicly on their sustainability performance. In the words of a past Chair of the Board of Directors:

The GRI is a unique, multi-stakeholder organization founded on the conviction consistent, regular and comparable reporting provides transparency and can be a powerful catalyst to improve performance. (ibid.)

GRI's reporting framework is intended to be "a universally-applicable, comparable framework in which to understand disclosed information" (ibid). Their framework has been in existence since 1997, when it emerged as the result of dialogue between individuals and organizations who were "interested in the development of a globally applicable framework for reporting on sustainable development" (Thurm 2006, 325). A revised version of the guidelines was released in 2002, and the third generation of the reporting guidelines (G3) came into being in 2006, after a multiyear, consensus-based process, involving more than 3,000 individuals from diverse stakeholders (GRI Reporting Framework Overview n.d.)* The principal goal of the framework is to facilitate the disclosure of information on sustainability performance in ways that are "meaningful, credible, and comparable" (GRI About GRI n.d.)

\footnotetext{
* The "Structured Feedback Process" is also detailed in Thurm 2006.
} 


\section{GRI in Detail}

The basic structure of the G3 framework is laid out in GRI's Sustainable Reporting Guidelines. (GRI G3 Reporting Guidelines 2006) Broadly speaking, the G3 framework addresses what to report and how to report it, and these two topic areas are addressed via principles, guidance, and a set of standard disclosures (including sustainability indicators). This suite of tools constitutes "a disclosure framework that organizations can voluntarily, flexibly, and incrementally, adopt" (GRI Reporting Framework Overviewn.d.).

The principles upon which sustainability reporting under G3 is based fall into two main groups (GRI G3 Guidelines 2006):

1. Reporting Principles for Defining Content

o Materiality - The information in a report should cover topics and indicators that reflect the organization's significant economic, environmental, and social impacts, or that would substantively influence the assessments and decisions of stakeholders (GRI Sustainability Reporting Guidelines n.d., 8).

o Stakeholder inclusiveness - The reporting organization should identify its stakeholders and explain in the report how it has responded to their reasonable expectations and interests (ibid., 10).

o Sustainability context - The report should present the organization's performance in the wider context of sustainability (ibid., 11).

o Completeness - Coverage of the material topics and Indicators and definition of the report boundary should be sufficient to reflect significant economic, environmental, and social impacts and enable stakeholders to assess the reporting organization's performance in the reporting period (ibid., 12).

2. Reporting Principles for Defining Quality

o Balance - The report should reflect positive and negative aspects of the organization's performance to enable a reasoned assessment of overall performance (ibid., 13).

o Comparability - Issues and information should be selected, compiled, and reported consistently. Reported information should be presented in a manner that enables stakeholders to analyze changes in the organization's performance over time, and could support analysis relative to other organizations (ibid., 14). 
o Accuracy - The reported information should be sufficiently accurate and detailed for stakeholders to assess the reporting organization's performance (ibid. 15).

o Timeliness - Reporting occurs on a regular schedule and information is available in time for stakeholders to make informed decisions (ibid., 16).

o Reliability - Information should be made available in a manner that is understandable and accessible to stakeholders using the report (ibid.).

- Clarity - Information and processes used in the preparation of a report should be gathered, recorded, compiled, analyzed, and disclosed in a way that could be subject to examination and that establishes the quality and materiality of the information (ibid., 17).

The challenge presented by any sort of fundamental principles (not just GRI's) lies not so much in articulating them as in actually implementing them. Thus, the G3 framework also provides a detailed explanation and a set of tests for each principle, so that an organization can ensure its reporting is consistent with the principles.

Crucial for any reporting organization, to say nothing of one so large as the United States Army, is establishing the scope of its report (i.e., setting boundaries for the report as a whole and setting the boundary for the individual performance indicators). G3 also provides guidance in these arenas, as follows (ibid., 17-19):

- A sustainability report should include in its boundary all entities that generate significant sustainability impacts (actual and potential) and/ or all entities over which the reporting organization exercises control or significant influence with regard to financial and operating policies and practices.

- These entities can be included using either Indicators of operational performance, Indicators of management performance, or narrative descriptions.

- At a minimum, the reporting organization should include the following entities in its report, using these approaches:

o Entities over which the organization exercises control should be covered by Indicators of Operational Performance. and

o Entities over which the organization exercises significant influence should be covered by Disclosures on Management Approach. 
Having understood the fundamental principles of reporting and established the boundaries of that reporting, the organization moves on to consider what disclosures it will make in its report. There are three distinct types of disclosures (ibid., 19):

1. Strategy and Profile: Disclosures that set the overall context for understanding organizational performance such as its strategy, profile, and governance.

2. Management Approach: Disclosures that cover how an organization addresses a given set of topics, to provide context for understanding performanœ in a specific area.

3. Performance Indicators: Indicators that elicit comparable information on the economic, environmental, and social performance of the organization.

While each of these is important and receives detailed attention in the G3 Guidelines, it is the performance indicators that are critical to this report. The performance indicators are "qualitative or quantitative information about results or outcomes associated with the organization that is comparable and demonstrates change over time" (ibid., 39).

There are three categories of indicators:

1. Economic: Indicators that "illustrate [the] flow of capital among different stakeholders [and the] main economic impacts of the organization throughout society" (ibid., 25).

2. Environmental: Indicators that "cover performance related to inputs (e.g., material, energy, water) and outputs (e.g., emissions, effluents, waste)... [and] performance related to biodiversity, environmental compliance, and other relevant information such as environmental expenditure and the impacts of products and services" (ibid., 27).

3. Social: Indicators that "identify key Performance Aspects surrounding labor practices, human rights, society, and product responsibility" (ibid., 29).

The GRI performance indicators may be found, in their entirety, at: http://www.globalreporting.org/ReportingFramework/ReportingFrameworkDownloads (under Indicator Protocols) The following table (using a sample from the environmental category), gives an idea of the nature of the indicators (ibid., 28): 
Table 1. GRI Energy Reporting Indicators

\begin{tabular}{|l|l|l|}
\hline \multicolumn{3}{|c|}{ Aspect: Energy } \\
\hline Core & EN3 & Direct energy consumption by primary energy source. \\
\hline Core & EN4 & Indirect energy consumption by primary source. \\
\hline Additional & EN5 & Energy saved due to conservation and efficiency improvements. \\
\hline Additional & EN6 & $\begin{array}{l}\text { Initiatives to provide energy-efficient or renewable energy based prod- } \\
\text { ucts and services, and reductions in energy requirements as a result } \\
\text { of these initiatives. }\end{array}$ \\
\hline Additional & EN7 & $\begin{array}{l}\text { Initiatives to reduce indirect energy consumption and reductions } \\
\text { achieved. }\end{array}$ \\
\hline
\end{tabular}

From Table 1, we learn that each of the categories of indicators is subdivided into relevant aspects. The reporting guidelines define "aspects" as: "The general types of information that are related to a specific Indicator category (e.g., energy use, child labor, customers)" (ibid., 39). In addition, we learn that indicators are themselves capable of subdivision into "core indicators," and "additional indicators."

In GRI Guidelines, core indicators are those "of interest to most stakeholders and assumed to be material unless deemed otherwise on the basis of the GRI Reporting Principles." In contrast, additional indicators are those "that represent emerging practice or address topics that may be material to some organizations but not generally for a majority" (ibid).

One can easily imagine that reporting under headings as broad as the above leaves wide latitude for what can be included. While that is true, each of the GRI performance indicators itself is supplemented by an indicator protocol that "provides definitions, compilation guidance, and other information to assist report preparers, and to ensure consistency in the interpretation of the Performance Indicators" (ibid., 40). By way of example, Appendix A presents the indicator protocol items and definitions that are aligned with the EN3 performance indicator (direct energy consumption by primary energy source) given above.

Still, the organization is left with many decisions in creating its report. Such decision include, but are not limited to:

- obtaining data

- making calculations

- selecting or creating estimation methods

- making estimates

- determining how much detail to include

- organizing and presenting the data. 


\section{GRI Application Levels}

NOTE: Reports intended to qualify for any of the levels shown must contain each of the criteria that are presented in the column for the relevant level.

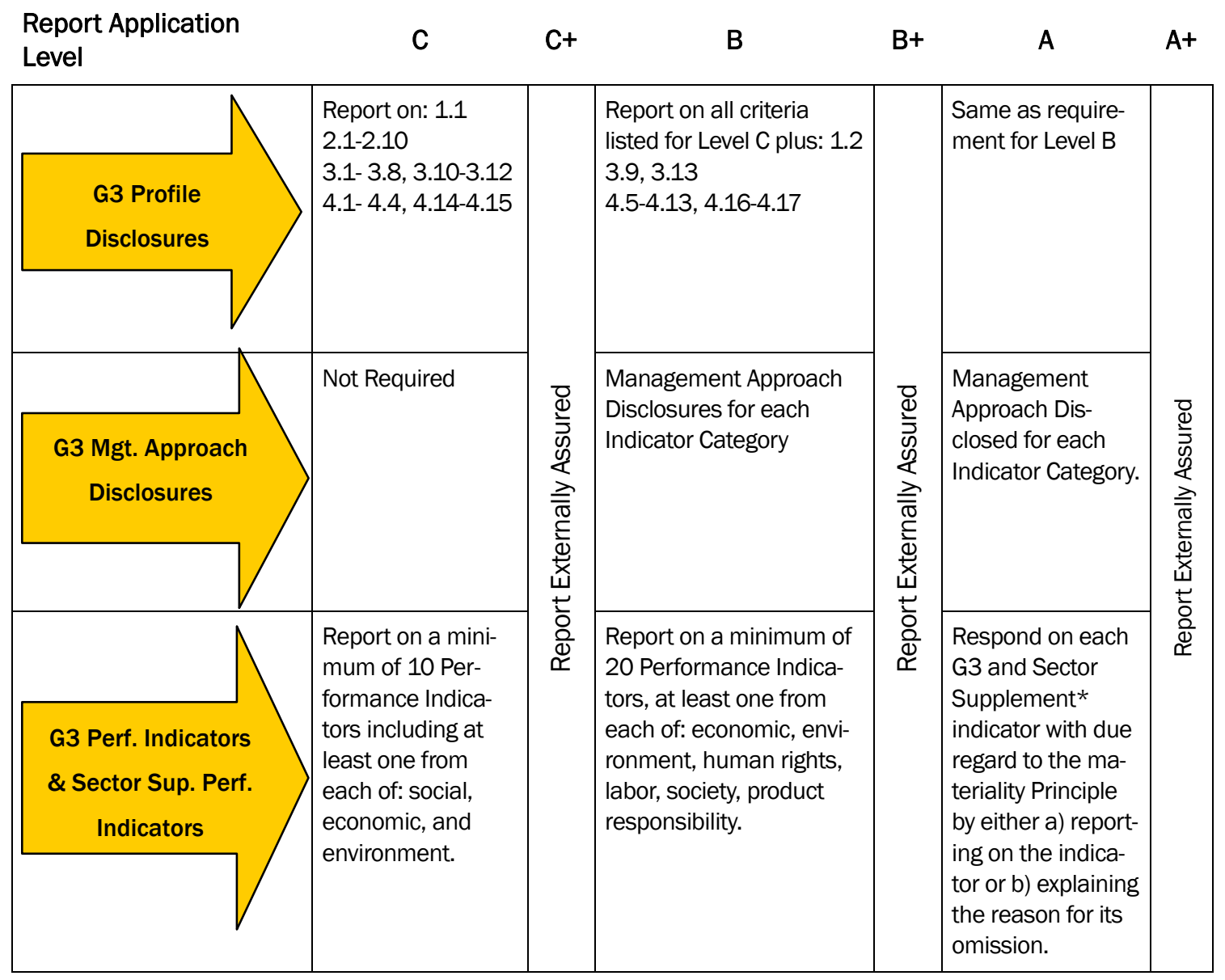

Figure 1. GRI application level criteria

(NOTE: table reproduced from GRI information with permission).

The notion of an application level allows an organization to declare to what level it has applied the GRI framework. Reporting organizations may report at any of three levels (C, B, or A), with "A" being the highest. Such self-declaration is required under GRI's G3 guidelines. An organization must rate its own report against the criteria in the GRI application levels, as reproduced in Figure 1.

The self-declaration process allows organizations to enhance their reports incrementally, allowing for beginning reporters, advanced reporters, and those that fall somewhere between the two. The levels are intended to 
make precisely clear what elements the organization is reporting on. The levels are also intended to: *

- Provide report readers with a measure of the extent to which the GRI Guidelines and other Reporting Framework elements have been applied in the preparation of a report.

- Provide report makers with a vision or path for incrementally expanding application of the GRI Reporting Framework over time.

To claim a "B" grade for its report, a reporting organization must make a complete set of G3 standard disclosures (see Appendix B), must disclose its management approach for each category of performance indicator, and must report on a minimum of 20 Performance Indicators. Of those 20 indicators, at least one must come from each of the following categories: economic, environment, human rights, labor, society, and product responsibility.

To claim an " $\mathrm{A}$ " grade, a reporting organization must do all that is required for a "B" grade. In addition, the higher grade report must respond to each core G3 and sector-supplement Performance Indicator (with due regard to the materiality principle), by either reporting on the indicator or explaining the reason for its omission.

In addition to the self-declaration process, an organization may also elect to engage a third party (or GRI itself) to offer a formal opinion on the organization's report. If such external assurance is used, a plus sign (+) is added to the letter that designates the report level.

\section{Sector Supplements}

We can now turn briefly to a discussion of sector supplements. When necessary, they are intended to be used in addition to (not in place of) GRI's reporting guidelines. These supplements address the specific needs of the following sectors individually (GRI Sector Supplements 2006):

- Airports

- Apparel and Footwear

- Automotive

- Electric Utilities

- Financial Services

- Food Processing

* GRI Application Levels, p. 1 
- Logistics and Transportation

- Mining and Metals

- Nongovernmental Organizations

- Public Agency

- Telecommunications

- Tour Operators.

Of this set of supplements, only two (Apparel and Footwear, and Electric Utilities) were designed specifically for use with the updated G3 guidelines. Even though the others were developed with the 2002 version of the guidelines in mind, they may still be used with G3. The user, however, may well come across some discrepancies and minor gaps, but these should not impede the process. ${ }^{*}$ There are stated plans to update the pre-G3 sector supplements. (GRI FAQs 2006)

\section{Review of GRI Environmental Indicators}

The Army may choose to use the GRI report in three ways: 1) as a public relations tool, 2) as a method to make information available to the public, and/ or 3) as a tool to improve Army sustainability.

In the spirit of the third option, we include here a brief discussion of reporting under each GRI environmental indicator. The discussion is far from comprehensive. Instead, our intent is to use a discussion of the environmental indicators to highlight some concerns and opportunities to be considered when using GRI reporting to document the Army's progress toward more sustainable operations.

This discussion does not answer the questions of where the data would come from, how difficult it would be to obtain, nor whether its usefulness would justify the level of effort necessary to collect a complete set of the data. However, these are all questions that will need to be answered in ongoing dialog, as the Army works to create a report that enhances its efforts to become more sustainable.

The GRI framework explains what type of data to collect, but it leaves open many details regarding data specifics. For example, a report could present representative examples of sustainability initiatives, or it could attempt to

\footnotetext{
* "Users may encounter some minor redundancies and inconsistencies when using pre-G3 Sector Supplements with the G3 Guidelines. However, detailed assessments have shown that these should not be significant impediments to effectively using the Sector Supplements with the G3" (GRI FAQs 2006).
} 
list all initiatives. Similarly, substantial effort might be required if a report included all protected areas and habitats. Further, the GRI framework does not address the value of data to the public, or its value for assessing the internal sustainability of the organization. The cost of the reporting effort should be weighed against the potential benefits, such as having a comprehensive list, and the possibility that some unexpected benefits may result from the effort.

If an organization plans to create updated GRI reports on a regular basis, it is also important to consider how to maximize the benefits of tracking changes over time. Long-term tracking can be a valuable tool for analyzing many aspects of sustainability. To produce a series of reports, an organization also should consider what should be reported in each version, and how it will be reported. For example, if an initiative is created in one year, but implemented in another, the first full year of results is seen in the third year. Because the benefits continue to increase over many years, how is the initiative reported each year, and at what point is it no longer reported?

Further details related to the GRI environmental indicators follows:

\section{EN1 Materials used by weight or volume}

GRI documents tell us that this indicator is meant to address the raw materials used in production. While this has only limited applicability to the Army, it also would seem not much more applicable to many companies. The U.S. and world economies are moving more and more toward a system in which each company adds an incremental value to the materials it receives. Also, the U.S. service economy is growing as the manufacturing base shrinks, meaning more companies use little or no raw materials.

While any effort to determine the resource requirements of an organization should be applauded, addressing this indicator in a meaningful way would be difficult, and it would be nearly impossible to cover exhaustively everything it could include. A standardized format for addressing some of the following questions would be useful:

- What does the term "materials" include? Are they consumables, durable goods, fixed infrastructure, etc.?

- How are manufactured goods accounted? Resources in a complex processed state less easily accounted for than raw materials.

- What is meant by the term "used"? Is an item consumed when it is purchased, first used, used up, disposed, demolished, etc.? What about 
things that sit on a shelf, like ammunition; when is a durable good "used"?

- What about utilities?

- How can the resource requirements of acquired services be covered?

Such services can create resource demands both directly and indirectly.

EN2 Percentage of materials used that are recycled input materials

"Recycled input materials" are those that replace virgin materials purchased or obtained from internal or external sources. For example, standard paper stock is commonly 30 percent or more recycled, but other materials are more difficult to assess. Unfortunately, it is not nearly so easy to determine the recycled content of most materials that the Army buys.

EN3 Direct energy consumption by primary energy source

EN4 Indirect energy consumption by primary source

Both of these may be the most important indicators of sustainability. Due to the amount of energy that is consumed, it is important to consider the environmental implications of where that energy comes from, and the impacts of using non-renewable energy.

While GRI requests reporting by the energy source, it is also useful to report consumption on a per-capita basis. Any data that can be collected on use per square foot or other unit is also useful. Metering of energy use by households and for specific activities is necessary for accountability. Such auditing and subsequent accountability would also lead to energy-saving improvements.

EN5 Energy saved due to conservation and efficiency improvement

EN6 Initiatives to provide energy-efficient or renewable energy based products and services, and reductions in energy requirements as a result of these initiatives

EN7 Initiatives to reduce indirect energy consumption and reductions achieved

Anecdotal examples of energy reduction and reporting of the resulting energy reduction can be useful, but it would be more useful to report the initial cost, implementation process, obstacles, and savings due to implementing energy reductions. Doing so would provide more complete information for expanded implementation within and outside the Army. 
Energy savings can be difficult to measure, because it requires comparison to a baseline. Given the rate of technology change, it may be difficult to identify clearly an appropriate baseline. Thus, it is important to explain how the baseline actually used was determined. Similarly, measuring indirect energy use by commuters, or for business travel, will be an approximation. The basis for that approximation needs to be made clear to the report reader.

\section{EN8 Total water withdrawal by source}

While it may be useful to know the total water used by the Army, the impact of use varies dramatically by location. Information on local water availability and consumption is far more useful than Army-wide data.

EN9 Water sources significantly affected by withdrawal of water

Environmental changes caused by water use, as well as water shortages, are important aspects of sustainability. Identifying "hot spots" is a critical step in assessing sustainability. A subjective identification of these hot spots may be adequate, but it may also be useful to set objective measures of "significantly affected." The Army may also need additional metrics to help determine whether its water issues are increasing or decreasing.

\section{EN10 Percentage and total volume of water recycled and reused}

It might also be useful to identify more precisely how the water is treated before reuse, and more specifically, how the water is recycled. A large portion is probably reused for irrigation (parade fields, golf courses, etc.), but it would also be instructive to know other ways recycled water is used. 
EN11 Location and size of land owned, leased, managed in, or adjacent to, protected areas and areas of high bio-diversity value outside protected areas EN12 Description of significant impacts of activities, products, and services on biodiversity in protected areas and areas of high biodiversity value outside protected areas.

EN13 Habitats protected or restored.

EN14 Strategies, current actions, and future plans for managing impacts on biodiversity.

EN15 Number of International Union for Conservation of Nature and Natural Resources (IUCN) Red List species and national conservation list species with habitats in areas affected by operations, by level of extinction risk

A comprehensive list of habitats and protected areas could be used for reporting on indicators EN11 and EN13. Data for EN 12, EN14, and EN 15 could be compiled independently of the particular protected areas, but the reporting would be strengthened by tying the data to the specific areas. Note that the Army might more usefully report on Threatened and Endangered Species.

EN16 Total direct and indirect greenhouse gas emissions by weight EN17 Other relevant indirect greenhouse gas emissions by weight EN18 Initiatives to reduce greenhouse gas emissions and reductions achieved

EN19 Emissions of ozone-depleting substances (ODSs) by weight EN2O NOx, SOx, and other significant air emissions by type and weight The reporting requirements described by GRI show no obvious gaps, but it is important for the Army to use a standard method for estimating emissions and determining what indirect emissions to include or exclude. Reporting also can be strengthened by identifying the primary activities that are the sources of emissions.

EN21 Total water discharge by quality and destination

The reporting can be strengthened by identifying the primary activities that are the sources of discharges.

EN22 Total weight of waste by type and disposal method

The reporting can be strengthened by identifying the primary activities that generate waste. 
EN23 Total number and volume of significant spills

The reporting requirements described by GRI show no obvious gaps.

EN24 Weight of transported, imported, exported, or treated waste deemed hazardous under the terms of the Basel Convention Annex I, II, III, and VIII, and percentage of transported waste shipped internationally

The reporting requirements described by GRI show no obvious gaps.

EN25 Identity, size, protected status, and biodiversity value of water bodies and related habitats significantly affected by the reporting organization's discharges of water and runoff

The reporting for EN25 would be strengthened if a standardized metric could be used to determine sensitive, receiving water bodies.

EN26 Initiatives to mitigate environmental impacts of products and services, and extent of impact mitigation

GRI reporting criteria for EN26 gives the reporting agency wide latitude in how it reports; the Army would need more detailed and standardized criteria to collect the applicable data.

EN27 Percentage of products sold and their packaging materials that are reclaimed by category

Although the products that the Army manufactures are generally not sold externally, the Army could look at the products it manufactures and how the associated packaging is disposed.

EN28 Monetary value of significant fines and total number of non-monetary sanctions for noncompliance with environmental laws and regulations

Indicator EN28 might be more useful if the Army could identify locations or activities that consistently receive fines and sanctions.

EN29 Significant environmental impacts of transporting products and other goods and materials used for the organization's operations, and transporting members of the workforce

Indicator EN29 might be more useful if the Army could identify locations or activities that dominate transportation needs. Addressing resulting transportation issues could provide the greatest benefit. 
EN30 Total environmental protection expenditures and investments by type.

The GRI criteria include a long list of expenditures to report. A more standardized format for presenting the data would be useful.

\section{Who Uses GRI?}

An organization called CorporateRegister.com maintains on its website a global directory of corporate social responsibility (CSR), sustainability, and environmental reports. The organization offers "access to the very latest reports as they are published, and provide[s] an archive of reports for each company featured. This is achieved through a combination of our own research and contact with companies" (CorporateRegister.com "About Reports" n.d.). CorporateRegister.com collects and provides these reports as a free service to registered users. A subset of the data that CorporateRegister.com make available can be obtained via their GRI Register. This register allows the user to establish which of the reports in CorporateRegister.com's vast dataset have been produced following either the GRI 2002 or G3 reporting guidelines.

CorporateRegister.com's GRI Register is run on the basis of the following general guidelines (CorporateRegister.com n.d.):

o We aim to include every relevant published corporate report, without limitations of country or company size and across all sectors, public and private. We actively research new reports where they are not provided directly by the reporting company.

o We will attempt to contact the companies we feature to request the most up to date information. In the absence of any contact we will maintain a company's free reporting profile through our independent, periodic research.

o We have had to take a view on what types of publications to include on the site. We feature reports and reviews - not brochures, marketing and related publications. We do not feature publications which are sales material, have no reference year, no quantitative data and no statement of policy.

o Some of our featured report profiles include sections from annual reports. These sections need to comprise at least 6 pages.

The site uses GRI's own guidance on what can be called a GRI report, and they recognize the following levels of GRI adherence (ibid.): 
G3

For a report to be considered aligned to any degree (high or low) with Version 3.0 of the Sustainability Reporting Guidelines (G3), the report maker must self-declare the level to which it has applied the GRI Reporting Framework. This system is known as the "GRI Application Levels" and has three levels: A, B and C.

\section{IA - In Accordance}

A report can be considered "in accordance" with the 2002 version of the Sustainability Reporting Guidelines if it meets five criteria, including: a statement from the corporate executive officer (CEO), a content index, and a response (or explanation of omission) to each core indicator. This report status is self-declared by the report maker, and can optionally be checked for accuracy by an auditor or GRI.

\section{CI - Contents Index}

A report maker includes a GRI Content Index (CI) to show readers in a quick and easy way where they can find data or responses to each disclosure in the 2002 Guidelines. Sometimes CIs also contain an explanation for why core content is not included in the report. The CI can be contained in the PDF version of the report and/ or the web-based version.

\section{Ref-only - With reference only}

Some reports state that they were developed "with reference to" or "based on" the 2002 Guidelines. Reports in this category do not contain a GRI Content Index or an In Accordance declaration. (NB. 2002 Ref-only reports were only accepted on The GRI Register up to September 2006, and no further 2002 Ref-only reports will be added.)

As of 23 J une 2008, CorporateRegister.com allows one to search for any of 17,252 CSR reports across 4,411 reporting companies. A search of the GRI Register with the parameters "All Sectors, All Affiliations, All GRI adherence" yielded 2,696 hits, where each hit is a report in which the GRI Register sees some degree of GRI adherence, consistent with the levels indicated above. Only 16 percent of the reports found in the CorporateRegister.com dataset are GRI-based.

Which organizations do GRI-based reports? To provide some examples of reporting organizations, we searched the GRI Register for the top 20 firms on Fortune magazine's 2008 list of the 1,000 largest American corporations (Fortune May 5 2008), for the top 20 firms on Fortune's 2007 Global 500 list of the world's largest corporations (Fortune J uly 272007 ), and for 
the top 20 firms on Interbrand's list of Best Global Brands - 2007 (Interbrand.com 2007). ${ }^{*}$

The percentage of top-20 companies reporting (excluding international companies for which only one or two national divisions report) varies from 50 percent to 75 percent, depending on the list.

It is also possible to search the GRI Register by business sector. A search with the parameters "Sectors: Government, Authorities \&Agencies, All Affiliations, All GRI adherence" yielded 28 hits, where each hit is a report that claims some degree of GRI adherence consistent with the levels of adherence indicated above.

Among these is the Sustainable Development Report October 2003 - October 2004, from the United Kingdom's Ministry of Defence, to which we will turn our attention in detail later in this report. A search on "Company Name: Army, All Sectors, All Affiliations, no GRI adherence" yielded four hits: three for the Royal Netherlands Army (Koninklijke Landmacht), and one (the eight-page Army Environmental Stewardship 2000 Progress Report) for the Department of the Army of the United States of America.

These results suggest that the GRI Register's search function is less than perfect, since each of these reports is flagged as belonging to the "Sector: Government, Authorities \&Agencies," but none of them was retrieved by our search on the parameters of "Sectors: Government, Authorities \& Agencies, All Affiliations, All GRI adherence." For this reason, we are reluctant to draw any conclusions from the results of the search by "Sectors: Government, Authorities \&Agencies.”

\footnotetext{
* The top 20 from each list appear in tabular form in Appendix C. For more information on the selection process, see Kiley 2007.
} 


\section{The Army's Reporting of Sustainability}

\section{The Army's Report for Fiscal Year 2007}

It is important that the Army become more transparent in its sustainability efforts by reporting in ways comparable to the industrial and private sectors, while also resonating with Army stakeholders in the public sector. A comprehensive effort at reporting is not only useful to communicate with stakeholders outside the Army, but also for internal organizational elements to see the larger picture from within.

Given the Army's mission, and the fact that there are no resources or efforts specifically targeted yet at sustainability reporting, this represents a significant challenge indeed. It is a challenge well worth the effort to overcome, especially when the Army uses the reports as a means of bringing about changes in its own ways of doing business.

The Army has embraced the challenge of reporting as it prepares Sustain the Mission, Secure the Future: The Army Sustainability Report for 2007". This report describes the Army's "triple bottom line-plus" (TBL), progress, made in implementing the 2004 Army Strategy for the Environment (ASE), as well as the Army's first GRI report.

By combining elements of the strategy, vision, goals, and reporting, the Army has taken great strides to link where it is with where it wants to be. The Army has few peers with comparable size and complexity who are undertaking such ambitious steps toward sustainability, and must forge paths where none currently exist.

One of the key components of The Army Sustainability Report that represents a new path for the Army is a GRI report. In previous sections the GRI was described. The following section examines how the Army responded to the GRI, then outlines further opportunities for reporting that can evolve to provide greater value on the path to sustainability.

\footnotetext{
* The comments and review in this document reference the 29 May 2008 draft version.
} 


\section{Review of the Army's Reporting of GRI Environmental Indicators}

This section reviews responses to the GRI Environmental (EN) indicators that were included as part of The Army Sustainability Report draft. The EN indicators are used because they provide a sufficient sampling for the purposes of this review, while also being in the most familiar domain. This exercise is difficult, not only because it is tedious, but also because it demonstrates that even though the Army has taken great strides, there remains much more that can be addressed.

The intent of the responses to the indicators is in accordance with GRI standards. The primary type of indicator response is a web link to reference material, with all of these being reports published in compliance with organizational drivers other than sustainability.

Appendix D details the review of the documents used as responses to the EN indicators. Since the Army had to make use of existing, publicly available data to respond to GRI indicators, it should be understood these reports and their data were prepared to answer questions perhaps only distantly related to sustainability. Thus, Appendix D also discusses the source's applicability to sustainability.

Appendix E takes a further step, examining documents from the links as responses to indicators, seeing if the answer could be readily found. There is some subjectivity to this evaluation. Of course, subjectivity inherent in responding to an indicator with a document versus a documented metric.

The Army Sustainability Report indicates that out of the 30 GRI EN indicators, the Army reports as follows: 10 fully reported, 6 partially reported, 13 not reported, and 1 not applicable.

After a review of the references for this report, a different tabulation has been reached: 2 fully reported, 6 partially reported, 21 not reported, and 1 not applicable. 
The listing in Table 2 explains how different conclusions were reached regarding the reporting status. Explanations of these conclusions can be found in Appendix E.

Table 2. Indicator reporting status comparison.

\begin{tabular}{|c|c|l|}
\hline Army GRI & Actual & Indicators \\
\hline$F$ & NR & EN11, EN12, EN14, EN15 \\
\hline$F$ & $P$ & EN13, EN22, EN26, EN30 \\
\hline$P$ & NR & EN7, EN19, EN24 \\
\hline$F$ & $F$ & EN20, EN 28 \\
\hline$P$ & $P$ & EN5, EN6, EN8 \\
\hline NR & NR & $\begin{array}{l}\text { EN1, EN2, EN3, EN4, EN9, EN10, EN16, EN17, EN18, EN21, EN23, } \\
\text { EN25, EN29 }\end{array}$ \\
\hline NA & NA & EN 27 \\
\hline
\end{tabular}

Key to report status for Table 2: $F=$ fully reported; $P=$ partially reported; $N R=$ not reported; $N A=$ not applicable.

Table 3 provides another way of looking at the review results, by listing which indicator responses are reported, partially reported, not reported, and not applicable. Note that some of the indicators listed as not reported could possibly be considered to be not applicable. Any indicators that the Army GRI report listed as NR or NA have also been shown with the same status in this review.

Table 3. Indicator reporting status (as per Appendix E)

\begin{tabular}{|c|l|l|}
\hline Total & Status & Indicators \\
\hline 2 & Reported & EN20, EN28 \\
\hline 6 & Partially reported & EN5, EN6, EN8, EN13, EN22, EN26, EN30, \\
\hline 8 & $\begin{array}{l}\text { Information provided is not } \\
\text { relevant }\end{array}$ & EN7, EN11, EN12, EN 14, EN15, EN19, EN24 \\
\hline 13 & Not reported & $\begin{array}{l}\text { EN1, EN2, EN3, EN4, EN9, EN10, EN16, EN17, EN18, } \\
\text { EN21, EN23, EN25, EN29 }\end{array}$ \\
\hline 1 & Not applicable & EN 27 \\
\hline
\end{tabular}

As one reviews the material in Appendices D and E, it is easy to get a sense of the overwhelming task one faces when mining the public data reported by the Army for use as indicators for sustainability, even for a reporting framework as general as that of GRI. The sources of reported data are many, diverse, dispersed, and divergently driven (and not driven to serve as the basis of measuring sustainability). But, with the Army's first attempt at GRI, there is a bold and encouraging beginning. 


\section{How the Army can Improve Reporting of Sustainability}

The Army Sustainability Report represents an important first step to add reporting to the Army's sustainability efforts. In the following section, we offer suggestions on how to build on the foundation the Army has laid in its 2007 report. The draft report package included descriptions of the Army Strategy for the Environment (ASE), "triple bottom line - plus" (TBL), as well as the Army's first GRI G3 report. Thus, the following discussion will consider the package, since the expectation is that this kind of report will be updated annually. It can also become an instrument for the Army and its stakeholders to review, in order to see trends over time.

\section{Link Strategy, Goals, TBL, and Reporting}

The Army Sustainability Report would benefit from stronger logical linkages that connect the ASE and TBL portions of the report with the GRI section. The report must be more elementary in its discussions, and more explicit in its findings. Such improvements should help the reader to see connections between the data presented, Army goals as they are articulated, and the progress that the Army intends to make. The report should make explicit how the information provided helps to make the Army more sustainable. If the intent is to use the GRI framework for reporting Army progress towards its goals as established in the ASE, the linkages between the two should be both logically and functionally clear.

\section{Accommodate the Unique Mission of the Army}

The Army Sustainability Report is explicitly aimed at the general public. By including a GRI report, it is also attempting to report the Army's efforts and progress toward sustainability, in the context of other organizations with vastly different missions than the Army.

The Army has unique characteristics, particularly operational activities carried out in a battle space. Simply put: to many outside the military community, the destructive methods used in Army operations are a stark contrast to most nonmilitary visions of a triple bottom line. This seeming discrepancy can be better acknowledged and put into perspective in the report. In addition, the Army is currently at war, making some of the types of reporting difficult to use in representing trends, since deployment for war results in huge use of resources and other significant impacts on the entire organization. 
As noted earlier, part of the GRI reporting process is to consider the boundaries of the report; application of the criteria that GRI provides indicates the operational activities of an Army at war still fall under what should be reported. Careful consideration needs to be given to how to quantify contingency operations in such a way that this seeming discrepancy is acknowledged and that the parts of the Army more comparable to nonmilitary organizations are kept in perspective.

The Army is not the only type of organization that has a mission that may appear to be at odds with concepts of sustainability. There are many corporations that create products that could be considered counter to achieving global sustainability. Automobile manufacturers and petroleum industries are perhaps the most obvious examples.

Automobile manufacturers may indeed address the global aspects of their products, and their reports include goals such as making more fuelefficient vehicles or developing vehicles that are not dependent on petroleum. Petroleum corporations generally report on the internal sustainability aspects of their companies, and avoid any global consequences of their products. Examples of this are the sustainability reports of the petroleum corporations Halliburton and Nexen. The Nexen report includes commentary from a third-party, the Nexen Expert/ Stakeholder Advisory Group, which provided a review of the company's sustainability report. Following are excerpts from that evaluation:

...the company should make a stronger statement on the link between its activities and climate change ..." and "We believe Nexen should further explore the possibility of quantifying end use emissions from the company's products and identify actions to reduce these emissions." (Nexen Inc. 2008, 46)

It is laudable that Nexen would include the third party evaluation in its report, and Nexen exhibited leadership in doing so. Certainly they have set a benchmark for transparency.

\section{Construct the Report as an Annual Update}

The Army Sustainability Report is to be the first of an annual series.* There are aspects of the report that can be better adapted to an annual report format that not only provides a yearly snapshot of the current status,

\footnotetext{
* As stated in the section entitled "Message from the Secretary of the Army and the Army Chief of Staff".
} 
but also is constructed to link previously-reported information. Such a combination would facilitate tracking trends.

In order that each successive version builds in a logical series, there are some types of content that may be left for another type of publication. For example, throughout the report, a number of vignettes were included that provided examples of how a given group addressed an ASE goal. These tell an excellent story, and also provide useful sharing of ideas with other installations, however the Army already has forums that share sustainability success stories and lessons learned.

In future Army sustainability reports, it may be helpful to decrease the focus on the particular project or program and to maintain a more generalized organizational emphasis that informs how Army goals, initiatives, and programs increase sustainability. Another example of content perhaps better left to other Army documents is the section on the U.S. Army Corps of Engineers Civil Works (CW) Programs. That section appears to have been extracted from another report focused on describing the civil works mission. As such, it is not germane to a report on progress toward sustainability. The information included does not provide insight as to how the CW Programs have been influenced or changed, in order to accomplish the CW mission in a more sustainable way.

\section{Incorporate Updates from the Installation Sustainability Program}

There was no information from the Army's Installation Sustainability Program (ISP) in The Army Sustainability Report. The Army's investment and efforts in ISP constitute an ongoing effort toward sustainability and merit inclusion in the report.

Installations in the ISP process are making tremendous strides in engaging the community and looking at issues in contexts well beyond their fence lines, with increasing effectiveness and cooperation. Since the report will be updated annually, the ISP section should include information that documents status over time, such as the progress that installations are making toward their goals, as well as reports of the ISP progression in general. An example would be listing, within that process, the number of installations adopting ISP and their status. 


\section{Actively participate in the evolution of the GRI G3}

As the Army explores how to document and report on its progress and to better accommodate its uniqueness, it can work with the GRI to help evolve the G3 so that other organizations that share some of these characteristics can also take advantage of the Army's examples and leadership.

There are many ways to complete the GRI G3, yet still not provide information that provides a transparent picture of the organization's sustainability. The Army can lead by creating an example of how to more clearly address the sustainability issues for each GRI indicator, thereby creating more substantive reporting.

GRI maintains a list of organizational stakeholders, a group that the Army intends to join (U.S. Army 2008 draft, p. 6, footnote 2). GRI allows the members of its stakeholder groups to participate in the GRI's governance system.

In its 2007 report, the Army made a long-range public commitment to reporting under the GRI reporting framework by stating that 2007 was its first annual report. Army leadership may well want to consider using its position as an organizational stakeholder to initiate the development of a sector supplement, specifically for military organizations throughout the world that want to demonstrate their commitment to sustainability by regular public reporting.

\section{Scoring}

GRI's G3 reporting framework does not include any mechanism, such as an overall score, that would facilitate evaluation of the quality and meaningfulness of a report (other than a self-declaration of report quality, which is based merely on the number of report elements that the reporting organization responds to). The GRI framework leaves the question of the significance of what is reported and the significance of any given report itself entirely up to the reader. It is our considered view that adding a scoring function to the GRI framework would ultimately lead to more substantive reporting.

\section{Improve the data being used as Indicators}

As described above in the discussion of self-declaration, getting an " $\mathrm{A}$ " on a GRI report is simply a function of reporting on more items. The Army's 
experience with its own Sustainable Project Rating Tool (SPiRiT) suggests that obtaining an " $\mathrm{A}$ " on its report, though in itself laudable, may not be what the Army really needs to advance sustainability of its operations.

For example, the Army's early and forward-looking attempts to use the U.S. Green Building Council's Leadership in Energy and Environmental Design (LEED) program as part of its construction design process, were thwarted by the relative inapplicability of the rating system to Army needs. The consequence of that lack of fit between Army needs and available tools was SPiRiT, which in turn, resulted in changes to the LEED rating system.

The real question for the Army with respect to sustainability reporting may well be not how to produce an A-level report but rather how to adapt GRI's reporting framework in such a way as to make it more relevant to users like the Army.

GRI could be used not only to describe change, but also to drive it. This would be particularly true if the data collected and reported could be used to set goals that are well articulated, set at a scale that is appropriate, and are well tracked. Figuring out how to set goals appropriately, and to track performance well is a kind of leadership that would benefit the entire community of organizations who report on their efforts toward sustainability.

A previous section and Appendices $\mathrm{D}$ and $\mathrm{E}$ provide an in-depth review of the responses the Army submits for the GRI EN indicators. These responses generally provide little more than links to other reports or websites. Most of the linked documents are large, and some linked documents are referenced for multiple indicators. No explanation is given as to how the response to an indicator is derived from that link. The reason for the link, and the ability to know with certainty where in that link to find the response, is left entirely to the supposition of the reader.

If one of the reasons for GRI G3 reporting is transparency, then the information should be explicitly provided. As described earlier in this paper, the GRI outlines balance, comparability, accuracy, timeliness, reliability, and clarity as principles for defining reporting quality. As the Army's reporting evolves, it should strive toward indicators that have the following components:

1. A quantifiable metric - a real number. 
2. Documentation of the source or sources from which it was obtained. It also should be noted whether the source(s) changed methodologies or reporting since being previously referenoed.

3. Documentation of any calculations that were done in order to derive or adapt data from source(s) to the GRI indicator.

4. For indicators partially reported, not reported, or declared not applicable, explain how this status was determined.

By incorporating these aspects into GRI indicators, the Army will greatly enhance clarity and comparability from year to year in its own reports, as well as providing enough information on data provenance to allow comparison with other organizations' reports.

As the Army prepares metrics and indicators, it should incorporate further qualities to help it internally drive sustainability. This could be accomplished by looking at how well the given indicators could be used to inform policy decisions, support decisions on investments, or perform other actions relevant to the indicator.

The Army should take care in preparation of metrics or indicators with respect to how they are used to show trends over time. The report should make explicit how the information provided helps make the Army more sustainable. For example, in the Army Sustainability Report a table of trends is presented with percent changes in a three-year period. ${ }^{*}$ In such a list, the reader can see that some numbers went up and some went down. However, the reader cannot tell, for instance, if the " $8.4 \%$ reduction in facility energy use intensity" is good, bad, or indifferent in relation to the goal the Army set for itself. Furthermore, it is unclear if any given goal for reduction of energy use could be connected to the overarching sustainability of the organization.

Fortunately, there are more meaningful examples for report metrics in the report. For example, Solid Waste is reported in tons per year but also is given as a percent of recycling; Hazardous Waste and Toxic Release Inventory (TRI) releases are both reported by weight and indexed to net cost of Army operations. This is important not only for transparent reporting of what the numbers mean, but also for clarifying issues discussed above as a way to help readers understand the Army's operational status.

\footnotetext{
* The table is entitled "Summary of Trends for Key Army Environmental Performance Metrics (FY04 to FY07).
} 


\section{Transforming data and reporting to facilitate the basis of sustainability reporting}

The next steps to achieving a more sustainable Army require integration of grounding of vision and goals with data-driven knowledge that can provide baseline status, trends over time, decision support, and also help in identifying and prioritizing needs. The obvious key needed for this to work are the data that define the Army's status and how that status is changing.

The data currently used by the Army for reporting are those publicly available that have been collected and reported for purposes other than assessing sustainability. To be most useful, the data needs to be not high-level comprehensive roll-up summaries, such as provided for the GRI G3, but rather data streams that are intimate to individual business processes and that can not only be mined for rollups, but also used for metrics and decision making at levels below that of the Department of the Army.

The Army collects and reports massive amounts of data in the conduct of its operations, including data related to compliance with the numerous laws, orders, and regulations that govern its operations, and other requirements. As the Army incorporates sustainability into its operations, there are many opportunities to leverage existing reporting efforts in such a way as to provide valuable metrics. A further opportunity exists as the Department of Defense (DoD) responds to legislative and Government Accountability Office (GAO) directives and recommendations that are related to defense business transformation management.

At the heart of the DoD Enterprise Transition Plan (ETP) for defense business transformation is the Business Enterprise Architecture (BEA):

The driver for evolving the BEA is to produce an architecture that can be harnessed as an executive decision-making mechanism while simultaneously supporting the implementation of information technology systems and services. This Concept of Operations for Business Enterprise Architecture (BEA) Requirements addresses this objective by 1) outlining a new architecture development approach that addresses both top-down strategic requirements and bottom-up tactical requirements, and 2) expanding the governance process to encourage users and stakeholders to shape architecture form and content (U.S. DoD 2006).

The DoD ETP recognizes the tremendous size and complexity of the organization; for that reason, the BEA is designed to be implemented by or- 
ganizational components that can be federated into a comprehensive whole. An example of such a component is the Army Environmental Program (AEP) BEA target business requirements analysis that has been completed for the Environmental Quality (EQ) Program Group for the Army Office of the Assistant Chief of Staff for Installation Management. The plan includes enabling the transformation of the AEP enterprise "from a fragmented and stove-piped set of programs, system, and data to an enterprise that is results-based, performance-oriented, integrated, and netcentric" while also having as a purpose to "achieve the Army Strategy for the Environment" (U.S. DoD 2006).

In the process of developing the AEP enterprise transformation plan, all EQ reporting elements were identified and modeled. This provides an unambiguous inventory of data that clearly will have great value in any attempt to harvest sustainability metrics, going well beyond the current indicators used to satisfy the requirements for GRI G3 reporting. It is, therefore, a logical next step for the Army to investigate how it can leverage the considerable investment being made in the ETP by identifying how data in the BEA can be used as metrics that will help measure sustainability status, identify trends, and set goals.

The AEP EQ reporting, and thus data involved in its ETP plan, are primarily limited to the major command level through the headquarters level of the Army. Therefore, these data will have little or no relation to the installation level. However, there are changes that may also present opportunities for the Army to improve its means of transforming and mining these data to use as sustainability metrics. For instance, a number of installations are exploring the transition to Environmental Management Information Systems (EMIS). These systems are designed to help automate Environmental Management System (EMS) in a net-centric operation. They also are being designed to improve data consistency, quality, standardization, and portability. These elements of change all lend themselves to supporting the use of these reporting data as sustainability metrics. 


\section{Benchmarking}

\section{General Discussion}

We have presented a number of suggestions for how the Army might improve its report. We now turn to the question of benchmarking, both to set this report in a broader context and to provide a deeper analysis of ways in which sustainability reporting could be improved to the benefit of the Army. Such improvements would be a demonstration of its leadership among reporting organizations,.

\section{Definition}

The Oxford English Dictionary defines "benchmarking” as:

1. The action or practice of comparing something to a benchmark; evaluation against an established standard.

2. A process in which a business evaluates its own operations (often specific procedures) by detailed comparison with those of another business (esp. a competitor), to establish best practice and improve performance; the examination and emulation of other organizations strengths.

The second definition, comparing operations with those of another business, is the definition more often relevant to sustainability reporting. Comparison to an established standard would be preferable, but there are few standards established as the local, regional, and global benchmarks that are necessary to benchmark Army sustainability goals.

Operations that are quantifiable are the most easily benchmarked. Consumption of both renewable and fossil fuel-based energy; recycled, renewable, and non-renewable materials; and water are all quantifiable. Most of the GRI G3 economic and environmental performance indicators (in the sector supplement for government agencies) are quantifiable. Many of the G3 community performance indicators have been defined to be quantifiable, though due to the subjective interpretation of some metrics, about a third are not easily quantifiable.

This section will focus on sustainability benchmarks that are quantifiable. It will also focus on how benchmarking must be meaningful, with respect to sustainability, and how meaningful benchmarking is related to setting meaningful goals. 


\section{Army Sustainability Goals, and Reporting Using GRI}

The GRI reporting guidelines lend themselves to being used in benchmarking. As stated earlier, most of the parameters that are reported are quantifiable. It is interesting to note that the objectives stated in the Strategic Plan for Army Sustainability were not mentioned in the draft of the 2007 Army Sustainability Report. Those plan objectives are quantifiable, optimistically aggressive, and demonstrate that the Army is being aggressive in a meaningful pursuit of sustainability.

Regarding the diligent use of GRI guidelines, the Army does well when compared to other organizations. Few, if any, corporate sustainability reports follow the GRI protocol at the level of detail presented in the Army report. From the standpoint of using the GRI protocol as an organizational tool for reporting, the Army has demonstrated significant leadership, and has set that benchmark for other organizations.

\section{Using Reports from Other Organization as Benchmarks}

The current focus of the Army Sustainability Report is primarily on activities within troop installation cantonment areas, with some mention of the civil works mission. However, the Army is a diverse organization, encompassing munitions production, logistics, training soldiers, operations and construction within cantonment areas, and deployments and war fighting. The Army also has a civil works mission that includes control of U.S. waterways with the mission to: 1) control floods, 2) maintain navigation, 3) provide reservoirs for hydropower, water supply and recreation, and protect natural resources. Establishing goals and benchmarks for all of these operations is daunting indeed.

Benchmarking the Army's sustainability goals may not be limited to comparison with the goals of other national defense organizations and defense industries. Various components of army installations can be compared to other private-sector organizations.

It seems logical that many Army installation cantonment areas are comparable to small cities, generally in the 10,000 to 50,000 population range. Though in some ways, the Army cantonment area tends to mimic a larger city regarding movement of people. The population of a cantonment area or city grows during the work day, and then shrinks when the many workers go to homes that are off post or in the suburbs. The Army city has utility systems, power generation, housing, and retail areas. But the Army city 
does not usually have large commercial and heavy industrial areas, and Army installations routinely see sudden changes in population (unlike most cities).

Instead, considering these additional factors, the Army installation may be most like a large university. A university often has: a large number of transients, retail but no industrial, many buildings that have intermittent use, barracks-like dormitories with food service, power production, a command structure (administration), and similar age demographics. Universities are also similar in size to Army installations. Descriptions of two university sustainability reports are included in the section below.

Army training areas might be compared to large State or National parks and forests. People arrive at parks from other locations, sustain themselves within the park, engage in activities involving hiking and driving, then, after a few days, return to their homes. The staff is concerned with monitoring and managing the natural resources, while also keeping the resources available for other uses, such as recreation or harvests. These characteristics are similar to training areas - though Army training might impact the environment with a different intensity. Presently, published sustainability planning and goals are not yet available for the Army to reference.

There are many entities in the civilian sector that are equivalent to subelements within the Army installation cantonment areas - general retail, food service, power plants, water and wastewater utilities, office buildings, and so forth. Municipal sustainability plans may have set goals for what the Army would refer to as tenants. Also, many large civilian organizations may have set goals covering several aspects relevant to the Army. Among these are vehicle and equipment manufacturers (such as Toyota, Honda, Ford, and General Motors), and logistics organizations such as the United Parcel Service (UPS) and the U.S. Postal Service. The Army can learn much from these organizations regarding setting sustainability goals and establishing sustainable operations.

\section{Sustainability Reporting by Other Organizations}

The following is a brief discussion of sustainability reporting by other organizations that have operations similar to those in the Army. Discussion of each report includes: whether the report is organized to follow GRI guidelines; whether the report discusses benchmarks and goals; and, if so, whether they are meaningful for sustainability and relevant to the Army. 


\section{The United Kingdom "Ministry of Defence Sustainable Development Report"}

The United Kingdom (UK) Ministry of Defence (MoD) report for the period October 2003 to October 2004 does state that GRI reporting guidelines were one of the sources of reporting guidance used in preparing the report. GRI version G2 guidelines would have been used when the UK MoD report was prepared, explaining why the UK report is formatted differently than the U.S. Army report, and why the UK MoD report does not self-report its application level.

The UK report does state some specific goals of the organization (called "objectives") and does report progress towards those objectives, though most of the objectives are not described quantitatively. The objectives generally are not linked to global or local sustainability goals, nor is the reasoning for each objective explained.

Three examples of reported parameters compared to objectives are:

1. EMS Coverage

a. UKMoD - $64 \%$ of Estate covered

b. Objective - $80 \%$ of Estate covered by 2006

2. Biodiversity

a. UKMoD - $71 \%$ of Sites of Special Scientific Interest (SSSI) are in favourable condition. (England only)

b. Objective - $68 \%$ of sites in favourable condition by 2006

c. $95 \%$ by 2010

3. Climate Change

a. UK MoD - $6 \%$ energy purchased from renewable sources

b. 5\% drop in Cemissions since 1999-2000 (433,000tC)

c. Objective - To be in line with UK government-led objectives

\section{Australian "Defence Public Environment Report"}

The "Defence Public Environment Report" by the Australian government's Department of Defence does not follow GRI guidelines per se, but the authors did document their consideration of them, along with other guidance, when preparing the report. The Australian report is long on good intentions, but almost devoid of statistics or measurements of any kind. The exception is the section titled "greenhouse and energy efficiency." In that section, the report discusses greenhouse gas emissions for a base year, a short-term goal for reduction (by total mass), and progress toward that goal. The reasoning behind setting this goal is not discussed. 


\section{The University of North Carolina Chapel Hill 2007 Campus Sustainability Report}

The UNC Sustainability Report does not follow GRI guidelines, nor does it make reference to any other reporting format or framework. The report does not discuss benchmarks, and does not reference specific goals for most of the UNC sustainability efforts. There is no reference to a formal sustainability plan, nor are the economic aspects of the sustainability efforts tabulated in a manner that could be used for comparison. A few significant goals are mentioned, such as the greenhouse gas reduction goal to become "climate-neutral by 2050." The contents of the report are largely anecdotal in nature (describing numerous individual efforts), though statistics are presented in the text that provide a certain degree of transparency.

That said, many of the UNC sustainability efforts might be of interest to the Army. UNC has taken an aggressive approach to sustainability in the areas of: 1) fossil fuel usage and greenhouse gas reduction, 2) energy conservation, 3) transportation, 4) new construction, and 5) waste recycling and reuse. The report goes into detail, explaining each of the UNC sustainability efforts, many of which promote involvement of the student body. Clearly, sustainability has become part of the UNC culture and in that respect, the school sets a great example to other organizations.

\section{University of Maryland Sustainability Report 2007}

The University of Maryland Sustainability Report does not follow GRI guidelines. The report does not discuss benchmarks or set quantitative sustainability goals. The report does discuss specific sustainability efforts, but does not in any way report a sustainability status like that of a GRIbased report. The report does not present sustainability efforts in a way that is useful to the Army for comparison purposes. 


\section{Advancing Sustainability Practice - Planning and Implementation}

To effectively implement a major improvement in a large organization's sustainability, there are a number of general steps to consider. These steps may include the use or development of methods or tools that: (1) provide awareness, (2) determine what resources are available for use within a sustainable environment, (3) establish a measure for the baseline usage of resources, (4) inform the decision process used for making sustainability improvements, or (5) measure subsequent progress and success toward goals or sustainability. Note that the application of these tools and processes may be different for sustainability project developers, decision makers, and other members of the organization.

\section{Tools and Approaches}

There are many approaches to managing and measuring status and progress toward sustainability. Each approach has distinct advantages and disadvantages that need to be considered, and then compared to the organization's desired path and endpoint. This report discusses reporting and benchmarking in some detail, but there are other sustainability tools that may also be considered. Some are commonly used, such as footprint calculators, and others are less common. A few of these alternatives are briefly described below.

\section{Awareness tools}

The goal of awareness is to motivate deeper, domain-specific reflection and to demonstrate the need for deeper analysis that can be used in decision making. The purpose of the awareness tool is to show that sustainability thinking is both possible and fruitful, and that it can occur without jeopardizing mission. The ISP process can be an effective awareness tool of a sort. Footprint calculators are another type of awareness tool.

Footprint calculators are widespread and prominent in the sustainability community. Most footprint calculators are based on relatively simple questions, and they make numerous approximations and assumptions about the resources actually used. Additional assumptions are made to determine a "footprint," or a land area equivalent, to supply the resources necessary for the estimated lifestyle. Among the footprint calculators that 
are readily available on the World Wide Web are those available at http://www.carbonfootprint.com/calculator1.html —or-

http://www.nature.org/initiatives/climatechange/calculator. Footprints are most useful for communicating simplified information at the awareness level. It is more difficult to use them for analysis, benchmarking, and guiding a path forward because the underlying assumptions and approximations may not be readily available to the user.

The footprint of humanity is widely considered to be significantly larger than the area of the earth, and by at least one measure, the United States has the second largest per capita footprint of all the nations in the world (WWF Living Planet Report 2006, p. 14).

The main objective of the footprint measure and other awareness tools is not only to make the user aware of this, but also to provide enough detail to increase concern and possibly change the user's behavior. These tools are relatively broad-brush and the user could identify easy opportunities for improvement or base general changes on the results from these tools. However, the tools do not provide enough detail to ensure that any and all changes to decrease a footprint will have equal value in improving sustainability, or even that all changes are actually beneficial. A footprint could be used to make rough calculations of an Army organization's need for raw inputs and the impact of their waste streams.

There is an increasing number of books that promote awareness of the challenge that the sustainability movement is seeking to meet, provide success stories, and suggest methods to tackle the challenge. For example, The Ecology of Commerce (Hawken 1994) outlines the challenge of the destructive components of many business practices and presents approaches to restore environmental functions. Ishmael (Quinn 1992) takes the sustainability novice on a journey of sustainability awareness. It presents human history in the context of the development of the human species, our rapid technological advancements and associated threats to the earth the systems that sustain us as a species. In Mid Course Correction, carpet magnate Ray Anderson was encouraged by customers to describe how his company, Interface, was improving the environment, and he turned his company into a leading environmental triple-bottom-line success story (Anderson 1996). 
Army Sustainability Planning

Many Army installations have undertaken the Installation Sustainability Planning (ISP) process with their local community to develop sustainability goals for their local area. As previously mentioned, Army Headquarters is also developing sustainability environmental goals for the Army as a whole.

The initial ISP goals set at the installation level have been primarily focused on reducing resource usage and increasing the supply of renewable resources. While these goals are quantitative, they are generally based on qualitative or even arbitrary criteria. They do not include a quantitative analysis of what is sustainable. These goals are created in the faith that the resulting change will be good. We do not know where we need to get to be sustainable, and we usually do not know how successful our efforts will be. Goals are important, but they must be appropriate to the location and must lead to a sustainable outcome. Army goals that are quantifiable must also be defensible with respect to achieving sustainability.

Strategic Plan for Army Sustainability (draft $\left.{ }^{\star}\right)$

The draft Strategic Plan lists approximately 30 tasks with short-term, medium-term, and end-state targets that are organized under more general objectives. These targets are essentially goals.

In the Strategic Plan, the targets take the form of: specific metrics, assignments of responsibility, general guidance, and education. Some examples are:

- Specific metric: "Reduce the fuel by weight needed to be transported to deploy forces by $50 \%$ in 5 years."

- Assignment goal: "Annually report on progress in waste elimination and the investment needed to achieve greater reductions."

- General guidance example: "Incorporate the waste reducing practices within Army best practices as they are deployed."

However, similar to the ISP process, there is no indication whether the end state will actually be sustainable.

\footnotetext{
* A draft was prepared as a possible way the Army may formulate a strategy for sustainability. As a draft, references made to specifics herein may not be part of the final construction.
} 


\section{Baseline and progress studies}

Baseline studies evaluate, in some detail, the initial state of a given organization or process. They may also present the current status with respect to sustainability goals. Such studies should be appropriately reproducible and inexpensive so that they can be repeated easily in the future to identify the rate of success in achieving prescribed goals. Baseline studies are important in identifying sustainability goals for an organization and can also show sustainability successes by comparing the baseline with other organizations. Such studies can also help identify the "low hanging fruit" areas where rapid success can be achieved.

The Army Sustainability Report is a type of baseline report. The Sustainable Installations Regional Resource Assessment (SIRRA) (J enicek et al. 2004) is another type of baseline measurement. SIRRA is focused on identifying obstacles and gaps in sustaining the mission of military installations. The United States Government collects data for a broad array of measurements related to sustainability for the entire country - often at watershed or county levels. The Army has adopted a set of several dozen of these in creation of the SIRRA methodology and tool.

Adoption of such metrics ensures acceptability and a reduced cost of data collection. These metrics are relevant to mission, environment and community. Given its focus on regional resources, SIRRA cannot be a comprehensive assessment tool. Nevertheless, even regional sustainability indicators can be useful for analyzing the cumulative impact of Army operations on a region shared with other human activities. Note that while SIRRA does help to identify potential problems that might threaten installation operations, it does not include an analysis of the sustainability of a region's resource use or of any of the metrics for which data is collected.

\section{Process engineering}

Process engineering is an efficiency improvement tool but such tools are also useful in becoming more sustainable. The manufacturing and industrial community routinely performs assessments of their operations to identify opportunities for improvement. These assessments may not look comprehensively at indirect costs and usually do not include costs to others and society. 


\section{Mass balance}

For any given military process such as the operation of a personnel unit, or the production and eventual disposal of equipment, it is possible to track the movement of all mass from the time and place it is extracted from the environment to the time and place that it is placed back in the environment. This is called a mass-balance analysis.

Such analyses are easily used to measure the inputs of water to a unit, a community, a base, or a factory as well as to measure the generation of treated wastewater. The approach can be used to track any mass. J ames and Lahti (2004) propose four system conditions for sustainability that are based on a thorough understanding of the associated mass-balance. The authors state the following system conditions, "In the sustainable society, nature is not subject to systematically increasing: 1 . concentrations of substances extracted from the Earth's crust, 2. concentration of substances produced by society, 3 . degradation by physical means and, in that society, 4. human needs are met worldwide" (J ames and Lahti 2004, p. 23)

\section{Total cost analysis}

Total Cost Assessment (TCA) is an established method used by the environmental community, and it incorporates all costs in an analysis of a process, product, facility, etc. (Kennedy 1997). Information on the TCAce software tool is available at http://www.earthshift.com/tcace.htm.

The goal of TCA is to incorporate direct costs of the process normally considered, as well as all issues relevant to the TBL including indirect costs, costs to others, and societal and environmental impacts of the given process. Typically, TCA is focused only on costs and does not fully capture income and other positive aspects of a cost benefit analysis.

\section{Cost-benefit analysis}

A cost-benefit analysis is similar to TCA in its general approach to calculating costs, but it adds an evaluation of the resulting benefits. The results are usually presented in terms of a ratio of the costs and benefits. However, not all aspects of sustainability can be reduced to costs and benefits, especially in terms of a common unit such as dollars. 


\section{Prioritization}

Once sustainability improvements are determined to be beneficial, most will still require funding to implement. The Army does not have funds immediately available that are adequate to complete all that is necessary to become sustainable.

The result is that there must be a decision process for selecting priorities for what will be funded. There are many ways of determining priority. At one extreme, the projects might not even be compared to other sustainability projects on the installation, much less against projects at other installations. Budgets tend to subdivided by departments, and individual projects often are not compared across an organization. The result of such a "stove-piped" organizational processes is likely to be a diversity of projects with a wide range of merits and benefits.

Sustainability projects might then advance toward completion based on the proactive steps taken by the given department in initiating and convincing others to fund their sustainability activities. Also, such decentralization can offer more opportunity for the development of novel approaches and solutions.

What is lost in such a situation are incentives and mechanisms for solutions and innovations that cut across the arbitrary organizational and funding lines. At the other extreme is a top-down, network-level process that looks at the relative benefits of all projects and includes a clear, effective method for selecting the most advantageous projects.

\section{Barriers to change}

In the March 2006 Draft Strategic Plan, many of the measures and targets involved overcoming barriers to change. These included promoting sustainability, educating soldiers, updating policy and guidance documents, adopting principles, and changing reward and personnel evaluation criteria. For each sustainability initiative it is important to identify specific barriers and recommend approaches to overcoming them.

There are at least four categories of barriers:

- Policy: Rules say do it this way (or not that way).

- Practice: We only know how to do it this way; also, it's not broke, so let's not fix it. 
- Coordination: Parties that need to coordinate for success are supported by different funding lines and associated rules, which provide restrictions and disincentives for change through coordination.

- Rewards: Sustainability is not a part of most current job descriptions or in criteria used for evaluation of job performance.

The goal-setting process can be extremely effective upfront in overcoming many of the potential barriers. By communicating an overarching policy or ethic established by a higher authority, representatives from different offices under that authority can come together to chart a way into a successful and barrier-free future. However, not all needed goals can be determined top-down.

\section{Identification of risks and uncertainty}

All individuals and businesses take explicit or implicit account of risk. A business is most likely to focus on cost as its primary "bottom line" measure of risks. Even life safety concerns are frequently measured by cost. For the Army, cost is not the first priority - mission is. Strategies for considering risk to a mission are not the same as for financial risks. This creates a challenge to implementing and assessing sustainability that is unique to the Army. Methods are needed for considering sustainability-related risks to the mission.

Because systems can have their components so tightly interconnected, it can be virtually impossible to foresee all of the consequences of a proposed change. Solving one problem can eventually cause unexpected consequences. Adding a road to allow soldiers to arrive at their duty stations based on time to meet an mission requirement (e.g. a rapid deployment parameters) may ultimately result in the development of supporting services along those routes (such as shops, schools, day-care, or restaurants) that actually increase travel time. Changing an industrial process for energy efficiency might increase the need for raw materials. Adding a raw material to a chemical process that decreases costs and pollution might put the Army at risk if that raw material comes from an area of the world that destabilizes, making the material unavailable.

\section{Defining meaningful goals}

When organizations begin to think about sustainability, they often focus primarily on either reducing their use of the earth's resources and services 
(footprint) or setting goals for such reductions. Goal setting can result in a more sustainable organization.

However, if all we do is arbitrarily reduce the use of resources, we are simply being frugal. To be sustainable, the community or organization must go beyond frugality. While resource conservation can result in important improvements, as well as enhancing the perception of sustainability within the organization, the goals must be based on embracing a more holistic understanding of sustainability. An organization also needs to consider what is sustainable within its community and region, and even consider global sustainability. The key prerequisite for setting a goal is a thorough understanding of what endpoint needs to be reached to be sustainable.

For goals to be meaningful, they must be set considering specific global, regional, and local limits to sustainability. Perhaps this is best explained with the use of the following examples.

Fossil fuel consumption is a global issue. Setting a sustainability goal related to a fossil fuel requires assessing the availability of that fuel globally.

The availability of water, on the other hand, is quite different. Water is virtually unlimited - including salt water, two thirds of the earth is covered by water. Yet, locally, it is often a very limiting resource because transporting fresh water long distances may cost more than users are willing to pay. Thus, there is no need for a global water goal -- only local (or regional) goals are relevant. Because the Army encompasses numerous, varied water resource scenarios throughout the U.S. and the world, sustainability is not well served if the Army sets a universal water conservation goal and applies that goal to all locations. For instance, the water usage goal for an installation in an arid region, such as Fort Huachuca, Arizona would be unrelated to a goal set at the Rock Island Arsenal, located on the Mississippi River in Illinois.

How goals are defined must also be meaningful. Analogies can be the clearest way to communicate abstract ideas and the following analogy seems useful here.

Suppose you have a forest with 1,000,000 trees. Trees are harvested for lumber, energy, and other means of obtaining income or value. Further suppose that currently you are cutting 50,000 trees per year, but notice 
the forest keeps getting smaller. You want to set a sustainability goal so that the forest can provide value and income continuously. Do you:

1. Arbitrarily say that within 10 years you will decrease the harvest rate by 20 percent?

2. Look at how many trees are being cut from forests in other parts of the world, and use that as a goal?

3. Or, do you ask someone knowledgeable in local forestry how fast trees regrow in your forest's conditions without loss of the ability to remain healthy, and then adjust your goal to that?

Clearly, the local forester can make the most accurate determination of what is a sustainable harvest. He is able to consider local impacts on water quality, habitat for various species, the natural cycle of fires and regrowth, and many other considerations.

Setting a goal using an arbitrary percentile reduction is meaningless in this example. The key word here is "arbitrary." The Army would be well served by showing a consistent preference for goals that can be tied to a global, regional, or local resource limitation.

Benchmarking must also be done carefully. As implied in the above analogy, duplicating the established goal of another organization is pointless if both organizations do not have the same constraints.

Many Army installations have undertaken the Installation Sustainability Planning (ISP) process with their local community to develop sustainability goals for their local area. As previously mentioned, Army Headquarters is also developing a draft of similar sustainability goals for the Army as a whole (U.S. Army 2008).

The initial ISP goals set by installations have been primarily focused on reducing resource use and increasing the use of renewable resources. These goals are important, but installations insure that they are appropriate to the location and linked to a sustainable outcome.

Army goals must be defensible with respect to achieving sustainability. Setting meaningful goals is the most important challenge the Army faces as it looks at how to make its installations more sustainable. 


\section{Use of data}

It is clear that data are necessary for assessing footprints, establishing baselines, benchmarking, or performing benefit-cost analysis. It is difficult to become more sustainable without good data. The Army creates vast amounts of data that can be related to sustainability. These data can be used to develop a GRI sustainability report, The Army Sustainability Report, or to assess progress against The Strategic Plan for Army Sustainability.

Still, the question remains as to whether the right data are being considered. In The Bill J ames Baseball Abstract 1982, author J ames describes how he asked fundamental questions to determine what skills and capabilities will lead most effectively to a winning baseball team. His idea was initially a radical one - that an on-base percentage and a slugging percentage were far more important data than batting average. Data for calculating these alternative percentages weren't even publicly available at that time. Over 20 years later, these percentages are readily available, yet the batting average is usually most prominently displayed and focused on by the media. Is this based on its usefulness or a resistance to change?

In the book Moneyball: The Art of Winning an Unfair Game, Michael Lewis states that Bill J ames never intended for his book, The Baseball Abstract, to redefine the specific statistical measures used. Instead, Lewis said J ames had the broader goal of getting the baseball community to look more closely at how to measure baseball success and developing new statistical measures. For example, J ames proposed that errors were a very poor way to judge fielding prowess. While he suggested an alternative viewpoint on fielding, he never fully developed a usable statistical measure in his abstracts. He may have expressed less criticism of currently used statistical measures for evaluating pitchers, but Lewis noted that there still was no public discussion of statistics to determine when to bring in a relief pitcher nor how long to pitch a closer. While baseball management methods are changing (whether as a result of J ames' writings, computer processing capabilities, or both), there is still a heavy reliance on scouting opinion and other experience-based decisions.

Lewis's book provides an example of how difficult it is to change a reliance on certain data. He points out that the difference between a .275 hitter and a .300 hitter is about one hit every two weeks. Forty percent of the time, the .275 hitter actually will get more hits than the .300 hitter over this period, making the data not as valuable in giving the best picture of hitters. 
Also, notice that Lewis used batting average statistics in the example, even though he was aware of the arguments for using on-base and slugging averages.

As do the baseball leagues, the Army collects and reports vast amounts of data, driven by many needs and requirements. It is natural to begin making sustainability measurements using all that available data, but care must be taken to evaluate and adapt the type of data used so that it gives the best picture of sustainability. 


\section{Conclusions and Recommendations}

\section{Conclusions}

The Army has embraced the goal of becoming more sustainable, articulated a desire to be transparent on the path to sustainability, and adopted the GRI reporting framework to demonstrate its progress on that path. By taking these actions, the Army has made clear its commitment to be a leader in the reporting community.

There certainly is ample room in the reporting community for improved (i.e., more substantive) reporting. Improving by extending reporting scope in order to achieve a GRI A-level is a reasonable near-term goal for the Army, but even A-level reports will not of themselves lead to progress. Showing the reporting community how to set well-articulated, appropriately scaled goals and how to track progress against them is yet another way in which the Army can lead.

Great leadership will not be shown either by reporting or by goal setting. Instead, the challenge facing the Army (and the highest form of leadership it can demonstrate) is to figure out a systematic, elegant, reproducible method (or set of methods) for choosing between competing alternatives.

\section{Recommendations}

Reporting is a necessary task for engaging stakeholders, but it is only a small part of the process toward sustainability. A GRI report is not the vehicle to address most of the sustainability issues that concern the Army.

The Army could show leadership by promoting the improvement of GRI guidelines. While the GRI framework is useful for organizing and standardizing sustainability reporting, it falls short of providing enough guidance to measure an organization's sustainability. The Army should consider participation in ongoing efforts by the GRI to improve its guidelines.

The GRI framework leaves the question of the significance of what is reported, and the significance of any given report itself, entirely up to the reader. It is our considered view that adding a scoring function to the GRI framework would ultimately lead to more substantive reporting. 
Getting an "A" on a GRI report is simply a function of reporting on more items. Obtaining that "A," though laudable, may not be what the Army really needs to advance sustainability of its operations. As the Army continues to evolve its public reporting process, we recommend that reports be carefully reviewed with respect to GRI's principles for defining both content and quality.

The Army Sustainability Report would benefit from stronger logical linkages between the ASE and TBL portions of the report and the GRI section.

If the intent for reporting using the GRI G3 is to enhance transparency, then the information should be explicitly provided, including any types of analysis or aggregation used to take data from the source and to make it usable as a GRI metric. As the Army's reporting evolves, it should strive toward indicators that have the following components:

1. A quantifiable metric - a real number.

2. Documentation of the source(s) from which data was obtained. It should also be noted if the source(s) changed methodologies or reporting since they were referenced previously.

3. Documentation of any calculations that were done to derive or adapt data from source(s) to the GRI indicator.

4. For indicators partially reported, not reported, or declared not applicable, explain how this status was determined.

By incorporating these aspects into GRI indicators, the Army will greatly enhance clarity and comparability from year-to-year in its own reports, as well as provide enough information on data provenance to allow other organizations' reporting to be compared.

Army installations may be most like large universities in terms of demographics and infrastructure. From the standpoint of benchmarking, and possibly sharing lessons learned regarding the implementation of sustainability, the Army may benefit by a closer association with the university community.

Since the general public is the intended audience for Sustain the Mission, Secure the Future, the report must be more elementary in its discussions and more explicit in its findings. It should help the reader to see connections between the data presented, Army goals as they are articulated, and progress the Army intends to make. The report should make explicit how the information provided helps to make the Army more sustainable. This 
is important not only for most transparently reporting what the numbers mean but also for clarifying issues discussed above as a way to help readers understand the Army's operational status.

The Army collects and reports vast amounts of data, driven by many needs and requirements. It is natural to begin making sustainability measurements using available data; however, care must be taken continually to evaluate and adapt the type of data we use so it has the power to measure what gives us the best picture of sustainability.

Setting goals for reduction in resource usage and increasing the supply of renewable resources can benefit the Army even if the goals are not directly tied to a sustainable outcome. Setting a goal using an arbitrary percentile reduction is insufficient to serve sustainability. The Army would be well served by showing a consistent preference for goals that can be tied to a global, regional, or local resource limitation. It is also important to monitor how the goals are reached to ensure the mission is not compromised.

\section{Outlining the way forward}

Sustainability is not yet well-established in organizations as large and complex as the Army. However, the Army is already demonstrating leadership through strategy development, reporting efforts, and initiatives such as the Installation Sustainability Program. There is great potential for the Army to demonstrate further leadership both in achieving and in reporting sustainability. Initial steps to that end are:

Set meaningful goals by adopting the following points:

1. Goals are well articulated and defensible. They explicitly link to the Army's vision and include a discussion of how working toward them makes the organization more sustainable.

2. Goals are set at an appropriate level - the level at which decisions are made. Target goals so that the elements of the organization with the most leverage have the most responsibility for achievement.

3. Goals are tied to local, regional, and/ or global sustainability.

4. Goals are measurable and can be tracked.

5. Goals foster a coordinated and systematic approach.

Become an active member of the GRI community:

1. Work toward improving the scoring function of the GRI framework. Scoring should not focus on the number of items an organization reports 
against, but rather on the significance of the answer with respect to the reporting organization's own sustainability efforts.

2. Work toward the development of a sector-specific supplement for military organizations.

Improve reporting:

1. Do not make a goal of reporting on more items simply to earn an "A." The current GRI grading system is not a measure of sustainability. Instead, carefully consider the GRI indicators against which the Army currently reports, with a view to making the responses more substantive. At a minimum, use GRI's principles for defining content and quality to guide this analysis.

2. Report progress toward achieving goals, with goals that are measurable and can be tracked.

3. Do not depend on annual DoD energy and environmental reports as the only data sources when responding to GRI performance indicators. Identify better sources for sustainability indicators, while also coordinating with the on-going DOD Enterprise Transition Plan. Enhance the substantiveness of the Army's reports; identify and fill gaps in data collection.

Think in terms of long-term leadership:

1. Think of leadership both in reporting and in goal setting.

2. Establish a systematic, elegant, reproducible decision-making process to help choose between competing sustainability alternatives. 


\section{References}

Anderson, Ray C. 1998. Mid course correction: toward a sustainable enterprise: The Interface model. Atlanta, Ga.: Peregrinzilla Press.

Australia Department of Defence. 2008 Defence Environmental Strategic Plan 20062009. Available at http://www.defence.gov.au/environment/strat_plan.pdf

Bushman, Robert M. and Abbie J. Smith. 2003. Transparency, financial accounting information, and corporate governance. Federal Reserve Bank of New York Economic Policy Review April 2003: 65-87. Available at http://www.newyorkfed.org/research/epr/03v09n1/0304bush.html (accessed 15 August 2008).

CorporateRegister.com. n.d. Information on GRI reports. Available online at http://www.corporateregister.com/aboutreports.html (accessed 15 August 2008).

n.d. About GRI reports. Available online at http://corporateregister.com/gri/about.html\#notes (accessed 15 August 2008)

Fortune top 1,000 corporations. 2008. List available at http://money.cnn.com/magazines/fortune/fortune500/2008/full_list/index.html (accessed 15 August 2008).

Fortune global 500 list of corporations. 2007. List available at http://money.cnn.com/magazines/fortune/global500/2007/full_list/index.html (accessed 15 August 2008).

Global Reporting Initiative (GRI).About GRI. Available at http://www.globalreporting.org/AboutGRI (accessed 15 August 2008).

About GRI/ FAQs. using sector supplements and G3 Guidelines. Available at http://www.globalreporting.org/AboutGRI/FAQs/SecSupAndG3FAQs (accessed 15 August 2008).

Application levels. Available at http://www.globalreporting.org/GRIReports/ApplicationLevels

Benefit of GRI. Available at http://www.globalreporting.org/AboutGRI/JoinGRI/Benefits/ (accessed 30 September 2008).

Reporting guidelines, version 3 (G3). Available at http://www.globalreporting.org/ReportingFramework/G3Guidelines/ (accessed 15 August 2008).

Reporting framework overview. Available at http://www.globalreporting.org/ReportingFramework/ReportingFrameworkOverview/ (accessed 15 August 2008).

Reporting framework/ sector supplements. Available at http://www.globalreporting.org/ReportingFramework/SectorSupplements/ (accessed 15 August 2008). 
Hawken, Paul. 1994. The ecology of commerce: a declaration of sustainability. New York: Harper Business.

Interbrand best global brands. 2007. List available at http://www.interbrand.com/best_global_brands.aspx?year=2007\&langid=1000

J ames, Bill. 1982. The Bill J ames baseball abstract, 1982. New York: Ballantine Books.

J ames, Sarah and Torbjörn Lahti. 2004. The natural step for communities: How cities and towns can change to sustainable practices. Gabriola Island, B.C.: New Society Publishers. Natural step framework and more available at http://www.naturalstep.org/en

J enicek, Elisabeth M., Donald F. Fournier, William D. Goran, Natalie R. Downs, and Adam J . Sagert. 2004. The sustainable installations regional resource assessment (SIRRA) capability, Version 1. ERDC/ CERL TR-04-9. Champaign, IL: U.S. Army Engineer Research Development Center. More information about SIRRA at https://ff.cecer.army.mil/ff/sirra.do

Kennedy, Mitchell L. 1998. Total cost assessment for environmental engineers and managers. New York: Wiley.

Kiley, David. 2007. Best global brands. Business Week: August 6, 2007. Available at http://www.businessweek.com/magazine/content/07_32/b4045401.htm (accessed 15 August 2008).

Lewis, Michael. 2003. Moneyball: the art of winning an unfair game. New York: W.W. Norton.

Lloyd, Robert, J effrey Oatham, and Michael Hammer. 2007. 2007 global accountability report. London: One World Trust. Available at http://www.oneworldtrust.org/index.php?option=com_docman\&task=cat_view\&gid=82\&ltemid $=55$

Media Transparency. Tracks the impact of conservative philanthropy on the media, both through a database of grant information and through original research. http://www.mediatransparency.org/ (accessed 15 August 2008).

McCarrey, Deanna. 2002 Green accounting: a new route to corporate transparency?. California CPA: Sept. 1, 2002. Reproduced at Novica, in assoc. with National Geographic: http://www.novica.com/news/index.cfm?articleid=161 (accessed 15 August 2008).

Nexen, Inc. 2008. Nexen, Inc. 2007 sustainability report. Calgary, Alberta, Canada: Nexen, Inc. Available at www.nexeninc.com/files/sustainability/2007/2007NexenSR.pdf

One World Trust. 2008 Global accountability report indicators. Available at www.oneworldtrust.org/index.php?option=com_docman\&task=doc_download\&gid=254\&ltemid $=55$

Quinn, Daniel. 1992. Ishmael: a novel. New York: Bantam/Turner Book.

Sourcewatch.org. n.d. Greenwashing. http://www.sourcewatch.org/index.php?title=Greenwashing (accessed 15 August 2008). 
Tapscott, Don, and David Ticoll. 2003. The naked corporation: how the age of transparency will revolutionize business. New York: Free Press. Information taken from a review by Publishers Weekly available online at http://www.publishersweekly.com/article/CA326661.html?q=naked+corporation\#naked

Thompson, Clive. 2007. The see-through CEO. Wired: 15.04 (March 2007) available online at http://www.wired.com/wired/archive/15.04/wired40_ceo_pr.html (accessed 15 August 2008).

Thurm, Ralph. 2006. Taking the GRI to scale: towards the next generation of sustainability reporting guidelines. In Sustainability accounting and reporting. ed., S. Schaltegger, M. Bennett and R. Burritt. Dordrecht, The Netherlands: Springer.

Total Cost Assessment (TCA), methodology and software tool(TCAce). Information on Earth Shift web site at http://www.earthshift.com/tcace.htm (accessed August 2008).

Transparency International. About its global coalition against corruption. http://www.transparency.org/about_us (accessed 15 August 2008).

United Kingdom Ministry of Defence. 2004. Ministry of Defence sustainable development report 2003-04. Copy available at http://www.mod.uk/NR/rdonlyres/369C3718F72C-4C26-9357-BD30F87FBDED/0/mod_sd_report_03_04.pdf

United States Army. 2004. The Army strategy for the environment: Sustain the mission, secure the future. Washington, D.C.: Department of the Army. Copy available at www.sustainability.army.mil/overview/ArmyEnvStrategy.pdf

2008. Strategic plan for Army sustainability. (non-published draft from May 2008). Washington, D.C.: Department of the Army.

2008. The Army sustainability report FY 2007: Sustain the mission, secure the future. Washington, D.C.: Department of the Army, Office of the Assistant Secretary of the Army for Installations and Environment. Published 5 Sep 2008. http://www.aepi.army.mil/internet/FINALArmySustainabilityReport2007.pdf (For more information about current Army sustainability go to http://www.asaie.army.mil)

2007. Annual financial report. Washington, D.C.: Department of the Army. Archived at http://www.asafm.army.mil/fo/fod/cfo/afr/afr.asp

2007. Annual energy report. Washington, D.C.: Department of the Army. Available at http://army-energy.hqda.pentagon.mil/reporting/report.asp

United States Department of Defense. 2008. Defense business transformation. Information available at www.pentagon.gov/dbt/index.html (accessed 16 J uly 2008).

2007. Fiscal year 2007 defense environmental programs annual report to Congress. Washington, D.C.: The Office of the Deputy Under Secretary of Defense (Installations and Environment (ODUSD(I\&E)) Available at http://www.denix.osd.mil/portal/page/portal/denix/environment/ARC/FY2007

2006. Enterprise transition plan (ETP) and business enterprise architecture(BEA). Information available at http://www.defenselink.mil/dbt/products/Sept-06-BEA_ETP/etp/ETP.html (accessed 16 J uly 2008) 
U.S. Environmental Protection Agency. ECHO: enforcement and compliance online (a searchable online database of compliance reports). Available at http://www.epa-echo.gov/echo/compliance_report_water_icp.html

University of Maryland. 2007. University of Maryland Sustainability Report 2007. Available at http://www.sustainability.umd.edu/sustainability_report.pdf

University of North Carolina at Chapel Hill. 2007. UNC at Chapel Hill Sustainability Report. Available at

http://sustainability.unc.edu/Portals/0/Documents/2007\%20Sustainability\%20Report_web.pdf

World Wildlife Fund. 2006. The living planet report 2006 (ed., Chris Hails; sixth in a series). Washington, D.C.: WWF. Report available for free download at http://www.panda.org/living planet 


\section{Acronyms and Abbreviations}

\begin{tabular}{|c|c|}
\hline Term & Spellout \\
\hline ACAT & acquisition category \\
\hline AEP & Army Energy Program \\
\hline AFAR & Army-Federal Acquisition Regulation \\
\hline ANSI & American National Standards Institute \\
\hline AR & Army regulation \\
\hline ARC & Annual Report to Congress \\
\hline ASE & Army Strategy for the Environment \\
\hline AT\&T & American Telephone and Telegraph \\
\hline BEA & Business Enterprise Architecture \\
\hline BMW & Bavarian Motorwerks \\
\hline $\mathrm{BP}$ & British Petroleum \\
\hline C & Carbon \\
\hline CAA & Clean Air Act \\
\hline$C \& D$ & construction and demolition \\
\hline CEERD & U.S. Army Corps of Engineers, Engineer Research and Development Center \\
\hline CEO & corporate executive officer \\
\hline CERL & Construction Engineering Research Laboratory \\
\hline $\mathrm{Cl}$ & Contents Index \\
\hline CNG & compressed natural gas \\
\hline $\mathrm{CO}$ & carbon monoxide \\
\hline CSR & corporate social responsibility \\
\hline CW & Civil Works \\
\hline CWA & Clean Water Act \\
\hline DA & Department of the Army \\
\hline DLA & Defense Logistics Agency \\
\hline DoD & Department of Defense \\
\hline EMIS & Environmental Management Information Systems \\
\hline EMS & Environmental Management System \\
\hline EPA & Environmental Protection Agency \\
\hline EQ & Environmental Quality \\
\hline ERDC & Engineer Research and Development Center \\
\hline ERDC-CERL & $\begin{array}{l}\text { Engineer Research and Development Center, Construction Engineering Re- } \\
\text { search Laboratory }\end{array}$ \\
\hline ETP & [DOD] Enterprise Transition Plan \\
\hline FUSRAP & Formerly Utilized Sites Remedial Action Program \\
\hline FY & fiscal year \\
\hline GAO & Government Accounting Office \\
\hline GE & General Electric \\
\hline
\end{tabular}




\begin{tabular}{|c|c|}
\hline Term & Spellout \\
\hline GHG & Greenhouse Gas \\
\hline GPP & [DoD] Green Procurement Program \\
\hline GRI & Global Reporting Initiative \\
\hline HAP & Hazardous Air Pollutants \\
\hline IA & In Accordance \\
\hline IBM & International Business Machines \\
\hline INRMP & Integrated Natural Resources Management Plans \\
\hline ISO & International Organization for Standardization \\
\hline ISP & Installation Sustainability Planning \\
\hline IUCN & International Union for Conservation of Nature \\
\hline LEED & Leadership in Energy and Environmental Design \\
\hline LNG & liquefied natural gas \\
\hline LPG & liquid petroleum gas \\
\hline MoD & Ministry of Defence (UK) \\
\hline NOx & Nitrogen Oxide \\
\hline NR & not rated \\
\hline NSN & national supply number \\
\hline ODS & Ozone-Depleting Substance \\
\hline OMB & Office of Management and Budget \\
\hline OWT & One World Trust \\
\hline PDF & Portable Document Format \\
\hline POTW & Publicly Owned Treatment Works \\
\hline RCRA & Resource Conservation and Recovery Act \\
\hline SDD & Sustainable Design and Development \\
\hline SDWA & Safe Drinking Water Act \\
\hline SIRRA & Sustainable Installations Regional Resource Assessmen \\
\hline SPiRiT & Sustainable Project Rating Tool \\
\hline SSSI & Sites of Special Scientific Interest \\
\hline TAP & The Army Plan \\
\hline TBL & triple bottom line \\
\hline TCA & Total Cost Assessment \\
\hline TD & technical director \\
\hline TRI & Toxic Release Inventory \\
\hline UK & United Kingdom \\
\hline UNC & University of North Carolina - Chapel Hill \\
\hline UPS & United Parcel Service \\
\hline VOC & volatile organic compounds \\
\hline WBCSD & World Business Council for Sustainable Development \\
\hline WRI & World Resources Institute \\
\hline WWF & World Wildlife Fund \\
\hline
\end{tabular}




\title{
Appendix A: EN3 Indicator Protocol
}

\author{
The Indicator Protocol for EN3: \\ Direct energy consumption by primary energy source \\ Reproduced in its entirety, as permitted by GRI, except for chart of measurements,
}

(Source: GRI Indicator Protocols Set: EN, pp. 7-8)

\section{Relevance}

The ability of the reporting organization to use energy efficiently can be revealed by calculating the amount of energy it consumes. Energy consumption has a direct effect on operational costs and exposure to fluctuations in energy supply and price. The environmental footprint of the organization is shaped in part by its choice of energy sources. Changes in the balance of these sources can indicate the organization's efforts to minimize its environmental impacts.

Information on the consumption of primary energy sources supports an assessment of how the organization might be affected by emerging environmental regulations such as the Kyoto Protocol. The consumption of fossil fuels is a major source of greenhouse gas emissions, and energy consumption is directly linked to the organization's greenhouse gas emissions.

Replacing fossil fuel energy sources with renewable ones is essential for combating climate change and other environmental impacts created by the extraction and processing of energy. Supporting renewable and efficient energy technology also reduces the reporting organization's current and future dependency on non-renewable energy sources, and its exposure to volatility in prices and supply.

This Indicator (EN3) measures the reporting organization's consumption of direct primary energy sources. The Indicator covers scope 1 of the World Resources Institute/World Business Council for Sustainable Development (WRI/WBCSD) Greenhouse Gas (GHG) Protocol. Indicator EN4 measures the consumption of primary energy sources to supply the reporting organization with intermediate energy such as electricity, heating and cooling, etc. 


\section{Compilation}

2.1 Direct energy sources purchased

Identify primary energy sources purchased by the reporting organization for its own consumption. This includes:

- Direct non-renewable energy sources including:

o Coal

- Natural gas

- Fuel distilled from crude oil, including gasoline, diesel, liquefied petroleum gas (LPG), compressed natural gas (CNG), liquefied natural gas (LNG), butane, propane, ethane, etc.

- Direct renewable energy sources including:

o Biofuels

o Ethanol

o Hydrogen.

Note: Biomass is excluded from direct renewable energy sources for the purpose of reporting to the WRI/WBCSD GHG Protocol. For alignment with the WRI/ WBCSD GHG Protocol, direct CO2 emissions from the combustion of biomass should be reported separately.

\subsection{Direct energy sources produced}

Identify the amount of primary energy the reporting organization acquires by producing, extracting, harvesting, collecting, or converting it from other forms of energy in joules or multiples. This can include the same energy sources listed under 2.1.

\subsection{Direct energy sources sold}

Identify the amount of primary energy exported outside the reporting boundary in joules or multiples.

2.4 Calculate total energy consumption

Calculate total energy consumption in joules or multiples such as gigajoules (one billion joules or $10^{9}$ joules) using the following equation: 
2.5 Report total direct energy consumption by renewable primary source

Report total direct energy consumption in joules or multiples by renewable primary source.

2.6 Report total direct energy consumption by non-renewable primary source

\section{Definitions}

Renewable resources: Resources capable of being replenished within a short time through ecological cycles (as opposed to resources such as minerals, metals, oil, gas, coal that do not renew in short time periods).

\section{Documentation}

Information can be obtained from invoices, measured (or calculated) heat/ fuel accounting, estimations, defaults, etc. Amounts of joules can be taken directly or converted from invoices or delivery notes. Information about the combination of primary sources used to generate intermediate energy can be obtained from suppliers.

\section{References}

The Greenhouse Gas Protocol (GHG) Initiative - A corporate accounting and reporting standard (Revised Edition, 2004) of the World Resources Institute (WRI) and the World Business Council for Sustainable Development (WBCSD). See http://www.ghgprotocol.org/ 


\section{Appendix B: G3 Standard Disclosures}

(Portions reproduced with permission from:

GRI Sustainability Reporting Guidelines, Version 3, pp. 20-24)

\section{Strategy and Analysis}

1.1 Statement from the most senior decisionmaker of the organization (e.g., CEO, chair, or equivalent senior position) about the relevance of sustainability to the organization and its strategy.

The statement should present the overall vision and strategy for the shortterm, medium-term (e.g., 3- 5 years), and long-term, particularly with regard to managing the key challenges associated with economic, environmental, and social performance." (p. 20)

1.2 The reporting organization should provide two concise narrative sections on key impacts, risks, and opportunities.

Section 1 should focus on the organization's key impacts on sustainability and effects on stakeholders, including rights as defined by national laws and relevant internationally agreed standards. This should take into account the range of reasonable expectations and interests of the organization's stakeholders. (p. 20)

Section Two should focus on the impact of sustainability trends, risks, and opportunities on the long-term prospects and financial performance of the organization. This should concentrate specifically on information relevant to financial stakeholders or that could become so in the future. (p. 20)

\section{Organizational Profile}

2.1 Name of the organization.

2.2 Primary brands, products, and/ or services.

The reporting organization should indicate the nature of its role in providing these products and services, and the degree to which it utilizes outsourcing. 
2.3 Operational structure of the organization, including main divisions, operating companies, subsidiaries, and joint ventures.

2.4 Location of organization's headquarters.

2.5 Number of countries where the organization operates, and names of countries with either major operations or that are specifically relevant to the sustainability issues covered in the report.

2.6 Nature of ownership and legal form.

2.7 Markets served (including geographic breakdown, sectors served, and types of customers/ beneficiaries).

2.8 Scale of the reporting organization, including:

- Number of employees;

- Net sales (for private sector organizations) or net revenues (for public sector organizations);

- Total capitalization broken down in terms of debt and equity (for private sector organizations); and

- Quantity of products or services provided. (p. 21)"

2.9 Significant changes during the reporting period regarding size, structure, or ownership including:

- The location of, or changes in operations, including facility openings, closings, and expansions; and

- Changes in the share capital structure and other capital formation, maintenance, and alteration operations (for private sector organizations).

2.10 Awards received in the reporting period (p. 21).

\section{Report Parameters}

\section{Report Profile}

3.1 Reporting period (e.g., fiscal/calendar year) for information provided.

3.2 Date of most recent previous report (if any). 
3.3 Reporting cycle (annual, biennial, etc.)

3.4 Contact point for questions regarding the report or its contents (p 21).

\section{Report Scope and Boundary}

3.5 Process for defining report content, including:

- Determining materiality;

- Prioritizing topics within the report; and

- Identifying stakeholders the organization expects to use the report (p. 21-22)."

3.6 Boundary of the report (e.g., countries, divisions, subsidiaries, leased facilities, joint ventures, suppliers) (p. 22).

3.7 State any specific limitations on the scope or boundary of the report.*

If boundary and scope do not address the full range of material economic, environmental, and social impacts of the organization, state the strategy and projected timeline for providing complete coverage.

3.8 Basis for reporting on joint ventures, subsidiaries, leased facilities, outsourced operations, and other entities that can significantly affect comparability from period to period and/ or between organizations.

3.9 Data measurement techniques and the bases of calculations, including assumptions and techniques underlying estimations applied to the compilation of the Indicators and other information in the report.

Explain any decisions not to apply, or to substantially diverge from, the GRI Indicator Protocols.

3.10 Explanation of the effect of any re-statements of information provided in earlier reports, and the reasons for such re-statement (e.g., mergers/ acquisitions, change of base years/ periods, nature of business, measurement methods).

\footnotetext{
* See completeness Principle for explanation of scope. (Footnote, p. 22)
} 
3.11 Significant changes from previous reporting periods in the scope, boundary, or measurement methods applied in the report (p. 22).

\section{GRI Content Index}

3.12 Table identifying the location of the Standard Disclosures in the report.

Identify the page numbers or web links where the following can be found:

- Strategy and Analysis 1.1- 1.2;

- Organizational Profile 2.1- 2.10;

- Report Parameters 3.1 - 3.13;

- Governance, Commitments, and Engagement

- Disclosure of Management Approach, per category;

- Core Performance Indicators;

- Any GRI Additional Indicators that were included; and

- Any GRI Sector Supplement Indicators included in the report (p. 22)."

\section{Assurance}

3.13 Policy and current practice with regard to seeking external assurance for the report. If not included in the assurance report accompanying the sustainability report, explain the scope and basis of any external assurance provided. Also explain the relationship between the reporting organization and the assurance provider(s) (p. 22).

\section{Governance, Commitments, and Engagement}

\section{Governance}

4.1 Governance structure of the organization, including committees under the highest governance body responsible for specific tasks, such as setting strategy or organizational oversight.

Describe the mandate and composition (including number of independent members and/ or nonexecutive members) of such committees and indicate any direct responsibility for economic, social, and environmental performance.

4.2 Indicate whether the Chair of the highest governance body is also an executive officer (and, if so, their function within the organization's management and the reasons for this arrangement). 
4.3 For organizations that have a unitary board structure, state the number of members of the highest governance body that are independent and/ or non-executive members (p. 22).

4.4 Mechanisms for shareholders and employees to provide recommendations or direction to the highest governance body.

Include reference to processes regarding:

- The use of shareholder resolutions or other mechanisms for enabling minority shareholders to express opinions to the highest governance body; and

- Informing and consulting employees about the working relationships with formal representation bodies such as organization level 'work councils', and representation of employees in the highest governance body.

Identify topics related to economic, environmental, and social performance raised through these mechanisms during the reporting period.

4.5 Linkage between compensation for members of the highest governance body, senior managers, and executives (including departure arrangements), and the organization's performance (including social and environmental performance).

4.6 Processes in place for the highest governance body to ensure conflicts of interest are avoided.

4.7 Process for determining the qualifications and expertise of the members of the highest governance body for guiding the organization's strategy on economic, environmental, and social topics.

4.8 Internally developed statements of mission or values, codes of conduct, and principles relevant to economic, environmental, and social performance and the status of their implementation.

Explain the degree to which these:

- Are applied across the organization in different regions and department/ units; and

- Relate to internationally agreed standards. 
4.9 Procedures of the highest governance body for overseeing the organization's identification and management of economic, environmental, and social performance, including relevant risks and opportunities, and adherence or compliance with internationally agreed standards, codes of conduct, and principles.

Include frequency with which the highest governance body assesses sustainability performance.

4.10 Processes for evaluating the highest governance body's own performance, particularly with respect to economic, environmental, and social performance (p. 23).

\section{Commitments to External Initiatives}

4.11 Explanation of whether and how the precautionary approach or principle is addressed by the organization.

Article 15 of the Rio Principles introduced the precautionary approach. A response to 4.11 could address the organization's approach to risk management in operational planning or the development and introduction of new products.

4.12 Externally developed economic, environmental, and social charters, principles, or other initiatives to which the organization subscribes or endorses.

Include date of adoption, countries/ operations where applied, and the range of stakeholders involved in the development and governance of these initiatives (e.g., multi-stakeholder, etc.). Differentiate between nonbinding, voluntary initiatives and those with which the organization has an obligation to comply.

4.13 Memberships in associations (such as industry associations) and/ or national/international advocacy organizations in which the organization:

- Has positions in governance bodies;

- Participates in projects or committees;

- Provides substantive funding beyond routine membership dues; or

- Views membership as strategic (p. 23)." 


\section{Stakeholder Engagement}

The following Disclosure Items refer to general stakeholder engagement conducted by the organization over the course of the reporting period. These Disclosures are not limited to stakeholder engagement implemented for the purposes of preparing a sustainability report.

4.14 List of stakeholder groups engaged by the organization. Examples of stakeholder groups are:

- Communities;

- Civil society;

- Customers;

- Shareholders and providers of capital;

- Suppliers; and

- Employees, other workers, and their trade unions.

4.15 Basis for identification and selection of stakeholders with whom to engage.

This includes the organization's process for defining its stakeholder groups, and for determining the groups with which to engage and not to engage.

4.16 Approaches to stakeholder engagement, including frequency of engagement by type and by stakeholder group.

This could include surveys, focus groups, community panels, corporate advisory panels, written communication, management/union structures, and other vehicles. The organization should indicate whether any of the engagement was undertaken specifically as part of the report preparation process.

4.17 Key topics and concerns that have been raised through stakeholder engagement, and how the organization has responded to those key topics and concerns, including through its reporting (p. 24). 


\section{Appendix C: Who Reports under GRI?}

\section{Who Reports under GRI?}

\begin{tabular}{|l|l|}
\hline $\begin{array}{l}\text { Top } 20 \text { from Fortune's } \\
2008 \text { List of 1000 largest American corporations }\end{array}$ & $\begin{array}{l}\text { Reports } \\
\text { Gnder GRI } \\
\text { Guidelines? }\end{array}$ \\
\hline Wal-Mart Stores & $\begin{array}{l}\text { Brazil and } \\
\text { Mexico } \\
\text { Only }\end{array}$ \\
\hline Exxon Mobil & Yes \\
\hline Chevron & Yes \\
\hline General Motors & Yes \\
\hline ConocoPhillips & Yes \\
\hline General Electric & Yes \\
\hline Ford Motor & Yes \\
\hline Citigroup & Yes \\
\hline Bank of America Corp. & Yes \\
\hline AT\&T & No \\
\hline Berkshire Hathaway & No \\
\hline J.P. Morgan Chase \& Co. & No \\
\hline American International Group & No \\
\hline Hewlett-Packard & Yes \\
\hline International Business Machines & Yes \\
\hline Valero Energy & No \\
\hline Verizon Communications & No \\
\hline McKesson & No \\
\hline Cardinal Health & No \\
\hline Goldman Sachs Group & No \\
\hline $\begin{array}{l}\text { Source of corporate names only is } \\
\text { http://money.cnn.com/magazines/fortune/fortune500/2008/full_list/index.html }\end{array}$ & \\
\hline & \\
\hline
\end{tabular}




\begin{tabular}{|c|c|}
\hline $\begin{array}{l}\text { Top } 20 \text { from Fortune's } 2007 \text { Global 500, } \\
\text { the world's largest corporations }\end{array}$ & $\begin{array}{l}\text { Reports under } \\
\text { GRI Guidelines? }\end{array}$ \\
\hline Wal-Mart Stores & $\begin{array}{l}\text { Brazil and } \\
\text { Mexico Only }\end{array}$ \\
\hline Exxon Mobil & Yes \\
\hline Royal Dutch Shell & Yes \\
\hline British Petroleum (BP) & Yes \\
\hline General Motors & Yes \\
\hline Toyota Motor & Yes \\
\hline Chevron & Yes \\
\hline DaimlerChrysler & No \\
\hline ConocoPhillips & Yes \\
\hline Total & Yes \\
\hline General Electric & Yes \\
\hline Ford Motor & Yes \\
\hline ING Group & No \\
\hline Citigroup & Yes \\
\hline AXA & Yes \\
\hline Volkswagen & Yes \\
\hline Sinopec & No \\
\hline Crédit Agricole & Yes \\
\hline Allianz & No \\
\hline Fortis & Yes \\
\hline \multicolumn{2}{|c|}{$\begin{array}{l}\text { Source of corporate names only is } \\
\text { http://money.cnn.com/magazines/fortune/global500/2007/full_list/index.html }\end{array}$} \\
\hline
\end{tabular}




\begin{tabular}{|l|l|}
\hline Top 20 from Interbrand's & $\begin{array}{l}\text { Reports under } \\
\text { Best Global Brands - 2007 }\end{array}$ \\
\hline Coca-Cola & Yes \\
\hline Microsoft & Yes \\
\hline International Business Machines (IBM) & Yes \\
\hline General Electric (GE) & Yes \\
\hline Nokia & Yes \\
\hline Toyota & Yes \\
\hline Intel & Yes \\
\hline McDonald's & Yes \\
\hline Disney & No \\
\hline Mercedes & No \\
\hline Citi & Yes \\
\hline Hewlett-Packard & Yes \\
\hline Bavarian Motorwerks (BMW) & Yes \\
\hline Marlboro (Philip Morris) & No \\
\hline American Express & Argentina Only \\
\hline Gilette & Yes \\
\hline Louis Vuitton & No \\
\hline Cisco & Yes \\
\hline Honda & No \\
\hline Google & No \\
\hline $\begin{array}{l}\text { Source of corporate names only is } \\
\text { http://www.interbrand.com/best_brands_2007.asp }\end{array}$ \\
\hline
\end{tabular}




\section{Appendix D: Review of Documents Referenced in Army Sustainability Report for GRI Environmental Indicators}

Most of the Army's responses to the GRI Environmental Indicators (EN) contained Internet links to other documents. In this review, the links provided for these indicators are briefly examined and described, noting where necessary an inoperable link at the time of this report. The descriptions focus on the applicability of the references to the GRI environmental indicators to which they were applied.

\section{FY07 Army Annual Financial Report}

http://www.asafm.army.mil/fo/fod/cfo/afr/currentyr/fy07afr.pdf

Indicators reported as fully or partially covered: EN13, EN14, EN30

The FY07 Army Annual Financial Report is 264 pages. It includes minimal coverage of sustainability related issues; includes data related to one GRI indicator, but incompletely covering it.

\section{FY 2007 Annual Energy Report}

http://army-energy.hqda.pentagon.mil/reporting/report.asp

Indicators reported as fully or partially covered: EN3, EN4, EN5, EN6, EN7, EN8, EN16, EN18, EN26

While most references to this report and the web link were removed from the then-current draft of the Army Sustainability Report, the Army Annual Energy Report is still mentioned (but noted that it is not publicly available, even at the above-mentioned Web site).

\section{Enforcement \& Compliance History Online (ECHO)}

http://www.epa-echo.gov/echo/compliance_report_water_icp.html

(Select “Defense Department," then "Army” under Federal agency dropdown menu.) 
Indicators reported as fully or partially covered: EN21

The only indicator referencing this website is listed as "Not Reported." It is noted that the information is not consolidated by the Army, but is collected at the installation level and reported to Environmental Protection Agency (EPA), where it is publicly available. Information directly addressing the indicator (total water discharge by quality and destination) was not located at the website. Preliminary inquiries suggest the website does not contain applicable information.

\section{FY07 DoD Energy Management Report, Army;}

http://www.acq.osd.mil/ie/irm/Energy/energymgmt_report/main.shtml ${ }^{*}$

\section{FY07 DoD Energy Management Report}

http://www.acq.osd.mil/ie/irm/Energy/energymgmt_report/fy07/DoD-Narrative-Final.pdf ${ }^{\dagger}$

Indicators reported as fully or partially covered: EN5, EN6, EN7, EN8, EN26

The FY07 DoD Energy Management Report is not Army specific and has little information for the Army. It includes a minimal coverage of sustainability related issues, including data related to, but incompletely covering, four GRI indicators.

\section{Installation Natural Resource Management Plans}

Indicators reported as fully or partially covered: EN11, EN12, EN13, EN14, EN15

The Installation Natural Resource Plans are not in the Sustainability Report, and there is no reference or web link indicating where or how to obtain them. The document says "Each Army installation maintains this information in an Installation Natural Resource Management Plan."

\footnotetext{
* These links are reproduced as given in the DoD report even though they appear inaccessible at the time of this technical report. Authors found all information about FY 07 DoD Energy Management Report available at http://www.acq.osd.mil/ie/energy/energymgmt_report/fy07/energymgmt07.shtml

$\dagger$ (See above explanation for link.)
} 


\section{FY07 DoD Annual Report to Congress: Defense Environmental Program}

https://www.denix.osd.mil/portal/page/portal/denix/environment/cleanup/ARC*

(The above link is given as listed in the report, but currently leads to an error page.)

https://www.denix.osd.mil/portal/page/portal/denix/environment/ARC

\section{Appendix A: Environmental Management Systems}

Indicators reported as fully or partially covered: EN26

Appendix A summarizes the implementation of EMS and ISO 14001 at Army installations. It does not include material specifically relevant to EN 26.

\section{Appendix G: Natural Resources}

Indicators reported as fully or partially covered: EN11, EN12, EN13, EN14, EN15

Appendix G summarizes the implementation status of Integrated Natural Resources Management Plans (INRMP) for each installation with significant natural resources. In 1997, the Sikes Act of 1960 was amended to require DoD to prepare these comprehensive plans to manage installation natural resources. The appendix also provides a general overview of the plans and additional information on related spending.

\section{Appendix T: Air Quality}

Indicators reported as fully or partially covered: EN20

Appendix T addresses air quality. It includes a descriptive overview and lists the Army's releases of the following air pollutants: hazardous air pollutants (HAPs), volatile organic compounds (VOCs), Nitrogen Oxide (NOx), EPA's Particulate Matter 10 (PM-10) standard, PM-2.5 standard, Sulfur Dioxide $\left(\mathrm{SO}_{2}\right)$, carbon monoxide (CO), and lead.

\footnotetext{
* While this link is no longer valid, it appears as listed in the Army Sustainability Report. The link immediately following is valid.
} 


\section{Appendix V: Enforcement Actions}

Indicators reported as fully or partially covered: EN28, EN30

This four-page appendix (with two pages relevant to the Army) presents basic information related to non-compliance with EPA, state, and local environmental laws and regulations. The appendix provides a descriptive overview, a table with the dollar value of fines assessed at the three levels of government, and figures with the numbers of new and closed enforcement actions in each of the last four years, and the dollar value of fines assessed at the three levels in each of the same four years. It does not break down the number of new and closed enforcement action by the three levels of government, nor does it indicate the number of open Army enforcement actions. It states the number of open DoD enforcement actions for FY06 and FY07. The report also indicates whether enforcement actions are increasing or decreasing for a number of categories and statutes including: "Clean Air Act (CAA); Clean Water Act (CWA); Safe Drinking Water Act (SDWA); Resource Conservation and Recovery Act Subpart C (RCRA/C), which addresses hazardous waste; RCRA Subpart D (RCRA/D), which addresses solid waste; RCRA Subpart I (RCRA/I), which addresses underground storage tanks; and Other."

\section{Appendix W: Solid and Hazardous Waste}

Indicators reported as fully or partially covered: EN22, EN24

This seven-page appendix (with two pages relevant to the Army) includes a descriptive overview that states the total Army solid waste, but not the portions of C\&D and municipal wastes, like the appendix includes for the DoD. Tables show the diversion rates for all Army solid waste over each of the last four years and the Army hazardous waste disposal for each of the last 11 years. The appendix does not list the types or quantities of different hazardous wastes.

\section{Appendix X: Green Procurement}

Indicators reported as fully or partially covered: EN26

Appendix X discusses various Executive orders, the DoD Green Procurement Program (GPP), and a Defense Logistics Agency (DLA) list of Environmentally Preferable Products but does not mention any Army-specific mitigation initiatives or results. 


\section{Appendix Y: Toxic Release Inventory for FY 2006}

Indicators reported as fully or partially covered: EN22

Appendix Y summarizes the Toxics Release Inventory (TRI) data. The descriptive overview states the total Army TRI releases and the change over 5 years. The releases are categorized as follows:

\begin{tabular}{|l|}
\hline On-site to Water \\
\hline On-site to Air \\
\hline On-site Underground Injection \\
\hline On-site Land \\
\hline Off-site to POTW \\
\hline Off-site Treatment \\
\hline Off-site Disposal \\
\hline
\end{tabular}

The appendix also lists the names and quantities of ten chemicals that the Army releases or transfers the most, the ten installations releasing or transferring the most, and some related statistics for each of the last six years. The appendix gives no further details on 262 other chemicals released.

\section{Appendix Z}

Indicators reported as fully or partially covered: EN19

The appendix discusses efforts to remove existing Ozone-Depleting Substances (ODS), non-recharge of others when used, recharge of others with only Army recovered stock (no commercial purchase), and continued use of one ODS Class I chemical. 


\section{Appendix E: Review of Army Sustainability Report responses for GRI EN indicators}

On the bold-face lines of type below that list each of the GRI's EN indicators, the reporting status given in the Army Sustainability Report is included in parentheses after the indicator title as: F, P, NR, or NA.* The Army's responses were reviewed by authors of this report, and many were deemed to be less responsive than was stated by the Army's reporting. A short summary of the reviewers' findings is included after each indicator.

\section{EN1 Materials used by weight or volume (NR)}

This indicator is listed as not reported.

EN2 Percentage of materials used that are recycled input materials (NR)

This indicator is listed as not reported.

\section{EN3 Direct energy consumption by primary energy source (NR)}

This indicator is listed as not reported, but a link to a reference document is provided.

\section{EN4 Indirect energy consumption by primary source (NR)}

This indicator is listed as not reported, but a link to a reference document is provided.

EN5 Energy saved due to conservation and efficiency improvement (P)

The FY07 DoD Energy Management Report includes the year-to-year change in the BTUs/ $\mathrm{ft}^{2}$ of building space.

\footnotetext{
${ }^{\text {* }} \mathrm{F}$ = fully reported; $\mathrm{P}=$ partially reported; $\mathrm{NR}=$ not reported; $\mathrm{NA}=$ not applicable;
} 
EN6 Initiatives to provide energy-efficient or renewable energy based products and services, and reductions in energy requirements as a result of these initiatives $(P)$

The FY07 DoD Energy Management Report provides anecdotal examples of such initiatives, but does not address the resulting, attributable energy savings. The percentage of electric energy from renewable sources is listed for FY07, which would allow comparison in subsequent years if the total electric consumption was also obtained.

\section{EN7 Initiatives to reduce indirect energy consumption and reductions achieved (P)}

The sustainability report refers to energy per unit area of facilities, but the GRI indicator refers to indirect costs such as travel, commuting, and subcontracted production. The_FY07 DoD Energy Management Report does not address GRI-defined indirect energy consumption costs.

EN8 Total water withdrawal by source (P)

The FY07 DoD Energy Management Report states the total potable water used by the army. It is not clear how much the Army withdraws for nonpotable use.

EN9 Water sources significantly affected by withdrawal of water (NR)

This indicator is listed as not reported.

EN10 Percentage and total volume of water recycled and reused (NR)

This indicator is listed as not reported.

EN11 Location and size of land owned, leased, managed in, or adjacent to, protected areas and areas of high bio-diversity value outside protected areas $(F)$

The Army Sustainability Report does not explain how the reader is supposed to access the Installation Natural Resource Management Plans.

The referenced document (FY07 DoD Environmental Report to Congress, Appendix G) does not report the location and size of land owned, leased, managed in, or adjacent to, protected areas nor does it report on areas of high bio-diversity value outside the protected areas. 
EN12 Description of significant impacts of activities, products, and services on biodiversity in protected areas and areas of high biodiversity value outside protected areas. (F)

The Army Sustainability Report does not explain how the reader is supposed to access the Installation Natural Resource Management Plans.

The referenced document (FY07 DoD Environmental Report to Congress, Appendix G) does not report a description of significant impacts of activities, products, and services on biodiversity.

\section{EN13 Habitats protected or restored. (F)}

The Army Sustainability Report does not explain how the reader is supposed to access the Installation Natural Resource Management Plans.

The referenced document (FY07 DoD Environmental Report to Congress, Appendix G) does not report habitats protected or restored.

The Army Annual Financial Report summarizes the number of acres of aquatic habitat restored, created, improved, or protected (pg 171) but does not provide similar information for land.

\section{EN14 Strategies, current actions, and future plans for managing impacts on biodiversity. (F)}

The Army Sustainability Report does not explain how the reader is supposed to access the Installation Natural Resource Management Plans.

The referenced document (FY07 DoD Environmental Report to Congress, Appendix G) does not report strategies, current actions, and future plans for managing impacts on biodiversity.

It seems unlikely that the Army Annual Financial Report would include an explanation of the Army's strategy for managing biodiversity. In further confirmation of this, the report does not even include the word "biodiversity." The section on the Civil Works program (pp 163-185) covers all aspects including navigation, flood/ storm damage reduction, hydropower, regulatory, environmental, emergency management, recreation, and water supply. 
EN15 Number of IUCN Red List species and national conservation list species with habitats in areas affected by operations, by level of extinction risk. (F)

The Army Sustainability report does not explain how the reader is supposed to access the Installation Natural Resource Management Plans.

The referenced document (FY07 DoD Environmental Report to Congress, Appendix G) does not report the IUCN Red List species and national conservation list species.

EN16 Total direct and indirect green-house gas emissions by weight (NR)

This indicator is listed as not reported, but it is noted that the information exists in an unnamed, nonpublic report.

EN17 Other relevant indirect green-house gas emissions by weight (NR)

This indicator is listed as not reported.

\section{EN18 Initiatives to reduce greenhouse gas emissions and reductions achieved (NR)}

This indicator is listed as not reported, but it is noted that the information exists in a nonpublic energy report.

EN19 Emissions of ozone-depleting substances (ODS) by weight (P)

The referenced document (FY07 DoD Environmental Report to Congress, Appendix Z) does not report the weight of emissions of ODS.

EN20 NOx, SOx, and other significant air emissions by type and weight (F)

The referenced document (FY07 DoD Environmental Report to Congress, Appendix T) individually lists the emissions weight of eight different pollutants.

EN21 Total water discharge by quality and destination (NR)

This indicator is listed as not reported. 


\section{EN22 Total weight of waste by type and disposal method (F)}

The FY07 DoD Environmental Report to Congress (Appendix W) includes the weight of municipal waste, C\&D waste, and hazardous waste for the Army. The report does not provide further details on more specific types of waste. It states the percentages and weights of waste landfilled and diverted from landfills for reuse, but no further details how it is reused. According to GRI criteria, the following categories should also be reported: Composting, Reuse, Recycling, Recovery, Incineration (or use as fuel), Landfill, Deep well injection, On-site storage, and Other (to be specified by the reporting organization).

FY07 DoD Environmental Report to Congress (Appendix Y) reports Toxic Release Inventory (TRI) and includes the release locations (air, water, land) and off-site transfers (publicly owned treatment works, for treatment and/ or disposal). The GRI criteria explanation gives no indication that TRI data should be reported for this GRI indicator.

\section{EN23 Total number and volume of significant spills (NR)}

This indicator is listed as not reported.

\section{EN24 Weight of transported, imported, exported, or treated waste deemed hazardous under the terms of the Basel Convention Annex I, II, III, and VIII, and percentage of transported waste shipped internationally. (P)}

Neither of the referenced appendices mentions the Basel Convention, so it is not transparent that either specifically addresses the GRI indicator. The Indicator is intended to address transport of hazardous waste across international boundaries.

The referenced report (FY07 DoD Environmental Report to Congress, Appendix W) provides summary information on the Army's solid and hazardous waste generated and Appendix Y summarizes TRI data.

\section{EN25 Identity, size, protected status, and biodiversity value of water bodies and related habitats significantly affected by the reporting organization's discharges of water and runoff (NR)}

This indicator is listed as not reported. 
EN26 Initiatives to mitigate environmental impacts of products and services, and extent of impact mitigation. (F)

The FY07 DoD Energy Management Report does not specifically address mitigation of environmental impacts. This 76-page report is primarily focused on energy issues, and not specific to environmental concerns. As there were no page numbers referenced by the Army Sustainability Report, it is difficult to be sure a complete answer is not present, but none was located. A word search on "mitigate" resulted in one use, "mitigate future liabilities." A word search on "environment" resulted in a few relevant passages regarding water-saving plumbing fixtures, installation of Energy Star products, energy-efficient lighting, sealing the building envelope, steam reduction during weekends and summer, and design to minimize pollution, and other environmental and energy costs. Most of this information is not Army-specific.

The FY07 DoD Environmental Report to Congress (Appendix A) summarizes implementation of Environmental Management Systems and ISO 14001 but does not discuss initiatives or extent of mitigation of environmental impacts.

FY07 DoD Environmental Report to Congress (Appendix X) discusses some Executive Orders, a DoD program, and a DLA list of preferable products but does not mention any Army initiatives for environmental mitigation. The appendix does not provide any information on extent of impact mitigation.

EN27 Percentage of products sold and their packaging materials that are reclaimed by category (NA)

This indicator is listed as not applicable.

\section{EN28 Monetary value of significant fines and total number of non- monetary sanctions for noncompliance with environmental laws and regulations. (F)}

This indicator is addressed adequately by the FY07 DoD Environmental Report to Congress (Appendix V) 
EN29 Significant environmental impacts of transporting products and other goods and materials used for the organization's operations, and transporting members of the workforce (NR)

This indicator is listed as not reported.

\section{EN30 Total environmental protection expenditures and investments by type. (F)}

There are two reference documents listed. The document for all Army, except Civil Works, (FY07 DoD Environmental Report to Congress, Appendix V) addresses EN30. However, the referenced Appendix V reports fines, but not environmental protection expenditures. In that same environmental report, Appendixes B- F report environmental expenditures by the following categories: environmental management, conservation, compliance, pollution prevention, and restoration, and not by the types of environmental expenditures listed in GRI EN30.

The document listed for Civil Works (FY07 Army Annual Financial Report - Civil Works Fund) is 264 pages and partially addresses this indicator. On page 164, a pie chart includes environmental expenditures for Ecosystem restoration, stewardship and the Formerly Utilized Sites Remedial Action Program (FUSRAP). It does not include military environmental expenditures. 


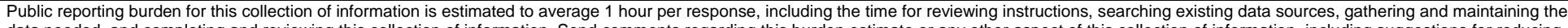

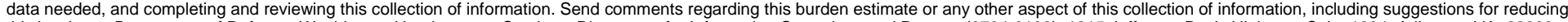

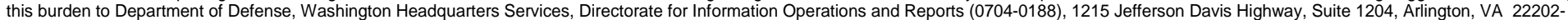

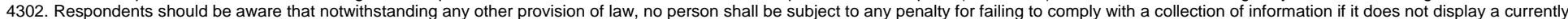
valid OMB control number. PLEASE DO NOT RETURN YOUR FORM TO THE ABOVE ADDRESS.
1. REPORT DATE (DD-MM-YYYY)
2. REPORT TYPE

14-04-2009

Final

\section{TITLE AND SUBTITLE}

Public Reporting and a More Sustainable Army

5a. CONTRACT NUMBER

5b. GRANT NUMBER

5c. PROGRAM ELEMENT

\section{AUTHOR(S)}

Stuart D. Foltz, Gary L. Gerdes, Michelle J . Hanson, David A. Krooks, and Chris C. Rewerts

\section{5d. PROJECT NUMBER MIPR 7LDATAEP17}

5e. TASK NUMBER

5f. WORK UNIT NUMBER

7. PERFORMING ORGANIZATION NAME(S) AND ADDRESS(ES)

U.S. Army Engineer Research and Development Center (ERDC)

Construction Engineering Research Laboratory (CERL)

PO Box 9005,

Champaign, IL 61826-9005

8. PERFORMING ORGANIZATION REPORT NUMBER

ERDC/ CERL TR-09-11

9. SPONSORING I MONITORING AGENCY NAME(S) AND ADDRESS(ES)

Army Environmental Policy Institute (AEPI)

1550 Crystal Drive, Suite 1301

Arlington, VA 22202
10. SPONSOR/MONITOR'S ACRONYM(S)

AEPI

11. SPONSOR/MONITOR'S REPORT NUMBER(S)

12. DISTRIBUTION / AVAILABILITY STATEMENT

Approved for public release; distribution is unlimited.

\section{SUPPLEMENTARY NOTES}

\section{ABSTRACT}

The United States Army has embraced the goal of incorporating sustainability into its operations, all the while meeting its primary mission to defend the United States. The Army also has indicated a desire to be both transparent and accountable, so it has adopted a recognizable reporting framework - as outlined by the Global Reporting Initiative (GRI). This review considers the Army's response to the GRI framework in its recent sustainability report, and points out opportunities to strengthen both. It also makes recommendations to improve the Army's reporting and goal-setting efforts by making them more meaningful and more measurable. Such changes are necessary to achieve full sustainability, especially given the many challenges facing an organization as large and diverse as the Army. While making these changes, progress must be communicated to both internal and external audiences - especially the general public in clear and substantive terms. This report further outlines how Army personnel can become leaders in global sustainability reporting and suggests that numerous benefits will result from setting well-articulated, appropriately scaled goals and tracking progress toward those goals over time.

\section{SUBJECT TERMS}

CASI, sustainability, Global Reporting Initiative (GRI)

\begin{tabular}{|c|c|c|}
\hline \multicolumn{3}{|c|}{ 16. SECURITY CLASSIFICATION OF: } \\
\hline $\begin{array}{l}\text { a. REPORT } \\
\text { Unclassified }\end{array}$ & $\begin{array}{l}\text { b. ABSTRACT } \\
\text { Unclassified }\end{array}$ & $\begin{array}{l}\text { c. THIS PAGE } \\
\text { Unclassified }\end{array}$ \\
\hline
\end{tabular}

NSN 7540-01-280-5500

\begin{tabular}{l|c|c} 
17. LIMITATION & $\begin{array}{c}\text { 18. NUMBER } \\
\text { OF ABSTRACT }\end{array}$ & \\
OF PAGES & 96 & \\
& &
\end{tabular}

Standard Form 298 (Rev. 8-98)

Prescribed by ANSI Std. 239.1 